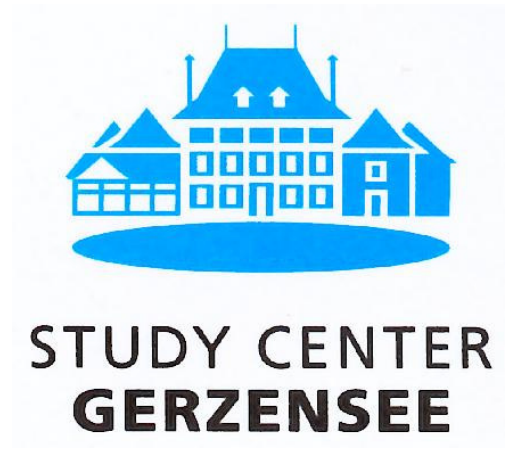

\title{
Transmission of Sovereign Risk in the Euro Crisis
}

Filippo Brutti and Philip Sauré

Working Paper 12.01

This discussion paper series represents research work-in-progress and is distributed with the intention to foster discussion. The views herein solely represent those of the authors. No research paper in this series implies agreement by the Study Center Gerzensee and the Swiss National Bank, nor does it imply the policy views, nor potential policy of those institutions. 


\title{
Transmission of Sovereign Risk in the Euro Crisis*
}

\author{
Filippo Brutti ${ }^{\dagger}$ \\ Philip Sauré \\ University of Zurich \\ Swiss National Bank
}

December 2011

\begin{abstract}
We assess the role of financial linkages for the transmission of sovereign risk in the Euro Crisis. Building on the narrative approach by Romer and Romer (1989), we use financial news to identify structural shocks in a VAR model of daily sovereign CDS for eleven European countries. To estimate how these shocks transmit across borders, we use data on cross-country bank exposures to sovereign debt. Our results indicate that exposure to Greek sovereign debt and debt of Greek banks constitute important transmission channels. Overall, financial linkages explain up to two thirds of transmission of sovereign debt in the Euro Crisis.
\end{abstract}

Keywords: Cross-country Transmission, Sovereign Risk, Financial Linkages, Euro Crisis, Narrative Approach

JEL Classification: F36, F42, F21, C30

${ }^{*}$ We would like to thank Nathan Foley-Fisher, Matthias Gubler, Sylvia Kaufmann, Christian Kascha, Carlos Lenz, Dirk Niepelt and Fabrizio Zilibotti. The views expressed in this paper are the author's views and do not necessarily represent those of the Swiss National Bank.

$\dagger$ Email: filippo.brutti@econ.uzh.ch

${ }^{\ddagger}$ Email: philip.saure@snb.ch. 


\section{Introduction}

In December 2009, with the global economy inching out of the Great Recession, the sovereign debt crisis hit Europe, soon putting into question the existence of the common currency. Problems to service public debt originated in peripheral Greece but spread to other countries at a pace and vigor that made experts wonder how "a small nation's refinancing difficulties [could] trigger a systemic crisis for the euro that brought global financial markets to the brink?" (Baldwin and Gros (2010)).

In the search for answers, financial linkages are the immediate and obvious suspects: the strong interdependence between banks and the heavy cross-border exposure to sovereign debt is said to have made sovereign default risk spread across Europe. Specifically, the prospects of a Greek sovereign default adversely affect European banks from the periphery to the core according to their exposure to Greek sovereign debt. ${ }^{1}$ By the same token, cross-border interbank lending matter: as a Greek sovereign debt crisis stresses the Greek banking system, counterparty risk rises for foreign creditors, affecting the latter's financial health.

By troubling national banking systems, Greek sovereign risk finally affects sovereign's credit conditions across Europe, since implicit bank guarantees quickly add to sovereign liabilities. Thus, the Economist writes that German officials aim to "protect German banks, many of which hold Greek bonds" and corresponding statements hold for other nations. ${ }^{2}$ Sketching the general picture, Christine Lagarde, Managing Director of the International Monetary Fund states that "[f]inancial exposures across the continent are transmitting weakness and spreading fear from market to market, country to country, periphery to core." ${ }^{3}$ By now, the prominent role of financial linkages for the transmission of Greek sovereign risk to European banking sectors and sovereigns is taken as an established fact.

The current paper quantifies the contribution of financial linkages to the transmission of sovereign risk, disentangling in particular the transmission through exposures to public debt and cross-border banking linkages. To this aim, we identify financial shocks that originate

\footnotetext{
${ }^{1}$ See Financial Times: "Greek contagion fears spread to other EU banks" (June 15 ${ }^{\text {th }} 2011$ ).

${ }^{2}$ See the Economist "Follow the Money" (April 16 ${ }^{\text {th }}$ 2011) "Latin Lessons" (April 23 ${ }^{\text {rd }}$ 2011) and Bloomberg: "France Risks AAA on Expanded EFSF Bailout Fund: Euro Credit" (18 ${ }^{\text {th }}$ October 2011).

"Global Risks Are Rising, But There Is a Path to Recovery": Remarks at Jackson Hole, August 27, 2011
} 
in Greece and analyze how sovereign default risk of European countries, measured by sovereign Credit Default Swaps (CDS), responds to these shocks. We relate the responses to the cross-border exposure to Greek sovereign debt and debt of Greek banks, data of which are provided by the Bank for International Settlement (BIS).

Our results show that financial linkages significantly contribute to the transmission of sovereign default risk. In particular, bilateral exposure to sovereign debt as well as cross-border bank linkages constitute economically and statistically significant transmission channels. Our preferred specification suggests that a 10 percent increase in the exposure to Greek debt increases the rate of cross-country transmission of sovereign risk by 1.9 percent. Similarly, a 10 percent increase of exposure to debt of Greek banks implies that sovereign CDS react 0.9 percent stronger to a Greek shock. A back of the envelope calculation based on these numbers shows that financial linkages explain up to two thirds of transmission of sovereign debt in the Euro Crisis.

Methodologically, we build on the narrative approach of Romer and Romer (1989). In particular, we study the impact of information shocks that are, first, relevant for Greek sovereign risk and, moreover, whose origin can be clearly attributed to Greece itself. These include the release of fiscal data, policy announcements and specifically severe debt downgrades. We make sure that, at these dates, there are no other information shocks to sovereign debt markets so that we can safely assume that all relevant information innovation can be attributed to Greece. ${ }^{4}$ Having identified fourteen of these "Greek shocks", we use a vector autoregression (VAR) model to relate the exposure to Greek debt to the rate at which Greek information affects sovereign CDS of a sample of European countries. In doing so, we exploit the time variation in debt exposure and we control for potential other channels such as trade through country fixed effects. We also include a number of financial factors as exogenous variables to control for common shocks.

The advantage of the narrative approach is that identification is achieved without assuming any specific pattern for cross-country spillovers. As noted by Rigobon (2003), standard identification assumptions, e.g. short-run, long-run or sign restrictions, are dif-

\footnotetext{
${ }^{4}$ Examples of these shocks are: "Greece's central bank governor said the country's budget deficit this year may exceed 12 percent of economic output or four times the EU ceiling." (October 10 ${ }^{\text {th }} 2009$ ); "Eurozone members commit to provide up to 30bn euros in loans to Greece over the next year." (April 12 $2^{\text {th }} 2010$ ) "Papandreou says Greece has reached a deal with the EU and IMF opening the door to a bailout in return for extra savings of 30 billion euros over three years" (May $5^{\text {th }} 2010$ ).
} 
ficult to defend in the context of cross-country transmission. A possible caveat of our narrative identification arises if on the days of our identified "Greek shocks" there are contemporaneous shocks to other countries, which nevertheless do not appear in the financial headlines. In this case, our estimate of the rate of transmission would be biased as we would erroneously attribute the response to all shocks to the events in Greece. To limit this problem, we take special care in reviewing the financial news and select the financially relevant Greek shocks. ${ }^{5}$

The narrative approach has been frequently used (see Romer and Romer (1989, 2004, 2010), Ramey and Shapiro (1998), Favero and Giavazzi (2007), Ramey (2011) for examples in economics and Thorbecke (1997) for finance), but it has also been disputed. Romer and Romer's (1989) original identification strategy through episodes of monetary contraction has been attacked as the effects of the selected events are hardly distinguishable from those of economic fundamentals, which are omitted from the econometric analysis (Hoover and Perez (1995)). Also, certain scenarios of the economic outlook may have caused the very action of the monetary authority itself, (Leeper (1997); see also the reply by Romer and Romer (1997). ${ }^{6}$ We argue that these standard lines of critique based on omitted variables and reverse causality do not apply to our specific setup. First, our selection of Greek events involves a detailed review of financial news and we make sure that no "omitted" news shocks occur on the same day. Other potential omitted variables may operate in the medium- and long-term, thus introducing trends in our CDS data. Since our daily CDS data are dominated by short-lived amplitudes and not by underlying trends, the induced bias is negligible. ${ }^{7}$ Similarly, the use of high frequency data releases us of the problem of reverse causality. In particular, a daily blip in the CDS cannot reasonably be believed to cause mayor political action in Greece on the same day (compare Table A1 in the Appendix). Finally, we also argue that our identification is intact even when events are partially anticipated, as we measure the rate of transmission based on the response of other European countries relative to the size of the contemporaneous shock in Greece.

\footnotetext{
${ }^{5} \mathrm{~A}$ detailed description of the data and the procedure of selection follows in Section 2.

${ }^{6}$ Leeper (1997) points out that the events Romer and Romer (1989) use to identify the response to monetary shocks (contractions of the FED) are predictable by past macroeconomic variables and unpredictable changes do not generate responses that look like typical effects of monetary policy. Romer and Romer (1997) argue that the results in Leeper (1997) are due to overfitting.

${ }^{7}$ We also refer to the lag structure of the VAR here, which generally captures trends of the dependent data. See the description of our autocorrelation tests in Section 4.
} 
A partial anticipation of future shocks has thus no effect on the estimates of this relative transmission.

The specific mechanism of cross-country contagion and transmission of financial turmoil is at the core of a large empirical and theoretical literature. In a recent survey article, Forbes and Rigobon (2002) have introduced a sharp distinction between contagion, which is defined by a fundamental change of cross-market relationship, and plain transmission of country-specific shocks. In that sense, we are much closer to the work of Forbes (2004) and especially Forbes and Chinn (2004), who do not measure contagion, but the channels of transmission. Contrary to the latter study, our results indicate that bank linkages are an important channel of transmission. ${ }^{8}$ Potential reasons for these differences are the relatively strong European financial integration and the large time variation of the cross-border debt structure. Finally, Forbes and Chinn (2004) analyze the role of total bank lending only, which in our study is generally less significant than its components (public and bank-tobank debt).

The unfolding Euro crisis is currently stimulating rich academic output, which can be cover here only partially. A large part of this literature has focussed on the role of financial linkages for the spreading of the crisis. Thus, Bolton and Jeanne (2011) develop a comprehensive theoretical analysis of transmission of sovereign debt through an integrated banking system. The authors point out that, while "diversification generates risk diversification benefits ex ante, it also generates contagion ex post." Using sovereign and bank CDS between 2007 and 2010, and a series of bank bailouts, Acharya et al (2011) provide evidence that a weak banking sector increases the default risk of the sovereign, showing, in particular, "that the announcement of financial sector bailouts was associated with an immediate, unprecedented widening of sovereign CDS spreads and narrowing of bank CDS spreads." Very much in line with these findings, Dieckmann and Plank (2010) find " a private-to-public risk transfer through which market participants incorporate their expectations about financial industry bailouts and the potential burden of government intervention." Focussing on the role of financial news, Bhanot et al (2011) report results that "point to the role of news announcements and the banking channel as important transmission channels in the

\footnotetext{
${ }^{8}$ Analyzing stock market returns, Forbes and Chinn find that bank channels are significant only in part of their specifications.
} 
crisis period." Finally, Arezki et al (2011) find that "sovereign rating downgrades have statistically and economically significant spillover effects both across countries and financial markets." The authors discuss several channels of spillover of sovereign risk across countries, pointing especially at "the holding of foreign sovereign debt by domestic banks..." as well as the claims of banks "on banks in other countries" (see also Blundell-Wignall and Slovik (2010) and Sy (2010)).

Our contribution to this empirical literature is twofold. First, building on the documented role of bank-to-bank and bank-to-sovereign linkages as transmission channels of sovereign risk, we take the broader perspective of the country level and analyze crosscountry spillovers and the role the national exposure rates played in the transmission of sovereign risk. Second, we are able to evaluate the transmission mechanism through the careful identification of the financial shocks that originated in Greece and through the time variation in national exposure rates.

The remainder of this paper is structured as follows. Section 2 describes our data in detail Section 3 lays out the empirical framework. Section 4 presents and discusses our main findings and Section 5 concludes.

\section{Data}

Our analysis requires a combination of three main data types: (i) a measure of sovereign default risk (ii) a measure of bilateral financial linkages and (iii) a classification of shocks that identifies, in particular, those of Greek origin. The key sources for the first and second type of data are Datastream and the BIS, respectively. We compile the third on our own.

Sovereign default risk. Our measure for a country's default risk is a five-year sovereign Credit Default Swaps (CDS) spreads, collected by CMAN and provided by Bloomberg. A CDS is essentially an insurance contract between two counterparties, typically traded over the counter. It transfers credit risk from one party, the buyer of protection, who pays "a regular fixed premium to the seller of protection in return for compensation contingent on the occurrence of a specified credit event" (Barclays Capital 2010). A credit event, in turn, is a general form of partial or full default by the borrower. In the case of a sovereign CDS the borrower is the sovereign of a country and the underlying debt security is a government bond of a certain specified type and duration. The most frequently traded 
Figure 1: Sovereign CDS Spreads

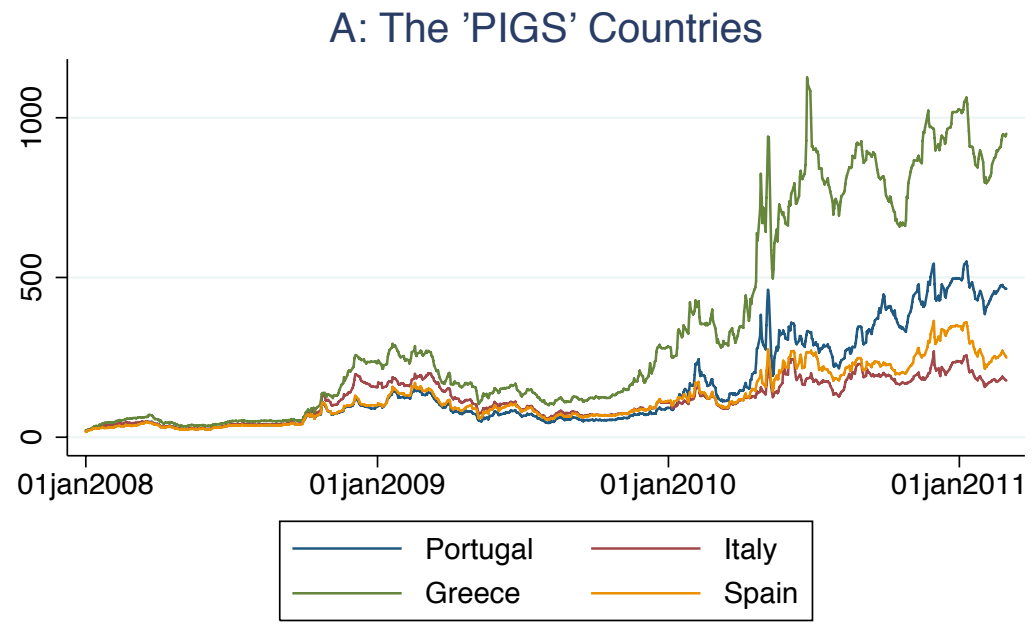

B: The 'Northern' European Countries

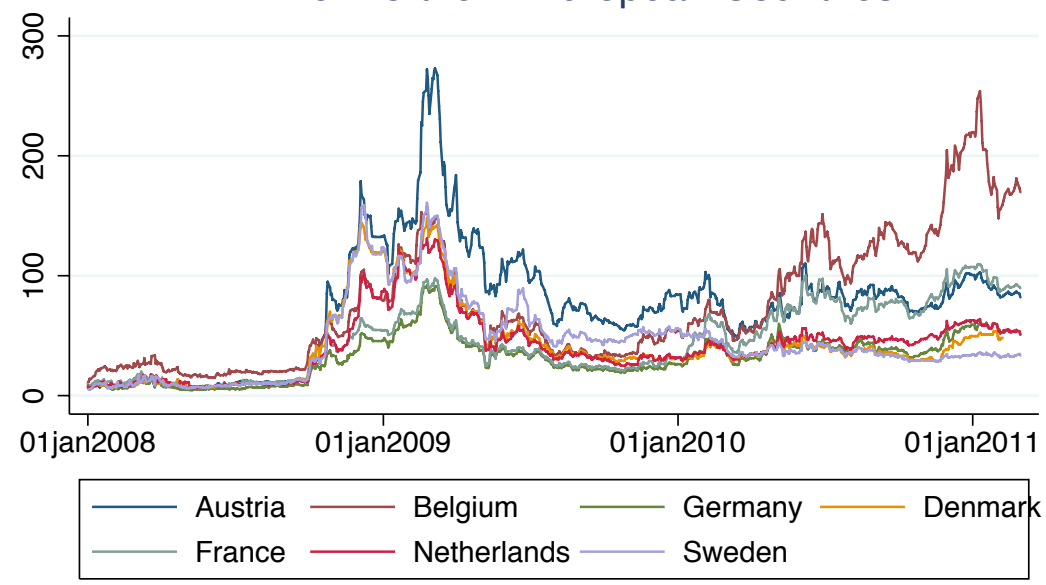

Five-year sovereign CDS of selected European countries at daily frequency from January 2008 to March 2011. Units of the vertical axis are basis points (a level of $100 \mathrm{bp}$ implies that it costs 0.01 Euro per year to protect one Euro outstanding debt over the five years). Source: Bloomberg. 
sovereign CDS typically refer to five-year on-the-run government bonds, which are consequently those commonly monitored, quoted and commented on in the course of the recent debt crisis. ${ }^{9}$ Our analysis relies on this particular specification of sovereign CDS.

Since 22 June 2009, the European CDS market applies the Standard European Contract (STEC) that fixes trading conventions. These specify that (i) quotations are for one of four fixed coupons: 25bp, 100bp, 500bp and 1000bp (ii) the definition of credit event comprises restructuring and (iii) the premium leg incorporates a full first coupon and accrued interest is paid at inception. Moreover, quoted spreads assume a flat credit curve to calculate the up-front payment and a recovery rate conventionally fixed at $40 \%$ for Western sovereigns (see Barclays Capital 2010). Although CDS do not capture default risk perfectly, recent literature has documented that they nevertheless constitute a quite reliable measure of and certainly are among the best available (Pan and Singleton (2008), Stulz (2010) and Fontana and Scheicher (2010)).

Figure 1 plots daily five-year sovereign CDS separately for PIIGS countries (Portugal, Ireland, Italy, Greece and Spain) and eight remaining "Northern" European countries for the period January 2008 to March 2011. These graphs are familiar to the reader of financial news: the curves not only track financial troubles at the height of the Great Recession, they also illustrate the buildup of the Euro crisis, in particular the market's assessment of a potential Greek sovereign default following the budgetary announcements by Greek authorities in fall 2009.

The figure suggests strong comovements of the countries CDS movements. Indeed, Table 1 reports pairwise correlations of log-changes for the fourteen countries. These pairwise correlations range between 0.6001 (Sweden and Greece) and 0.8915 (Italy and Spain) with an average of 0.7284. Besides the obvious effect of common factors (see Fontana and Scheicher (2010)) part of that correlation is likely to be generated by spillover effects from one troubled - e.g. Greece - to other countries of the sample.

Financial linkages. Bilateral banking linkages are measured using data from the Consolidated Banking Statistics of the BIS. This dataset includes data on bilateral financial claims, consolidated at the banking group level and broken down by nationality and four types of debt: (i) public debt, (ii) debt of private banks and (iii) private non-bank debt and

\footnotetext{
${ }^{9}$ See Packer and Suthiphongchai (2003), availabe at http://www.bis.org/publ/qtrpdf/r_qt0312g.pdf.
} 
Figure 2: Foreign Debt Exposure by Type

Eleven European Countries, 2007Q2-2011Q1 Immediate borrower basis
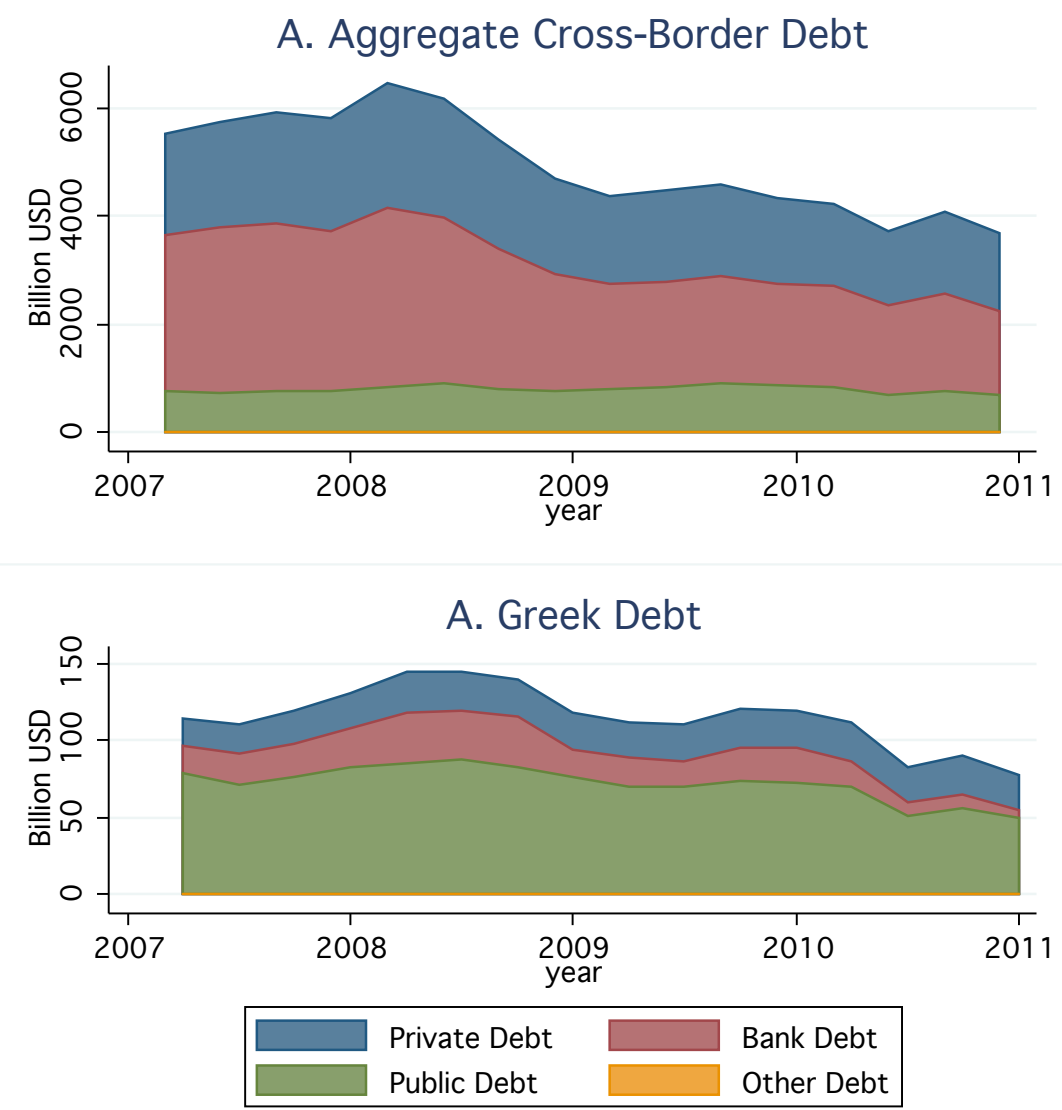

Exposure of BIS reporting banks to European Debt (top panel) and Greek debt (bottom panel) by type of debt: Public, Bank and Non-bank private, and Other. Quarterly data are reported on immediate borrower basis (for a comparison between immediate and ultimate borrower basis, see the Appendix). The set of 11 countries includes: Austria, Belgium, France, Germany, Greece, Italy, Netherlands, Portugal, Spain, Sweden and UK. Source: BIS, Consolidated Banking Statistics. 
(iv) other debt. The consolidated banking statistics exist since the late 1970s and provide a measure of country risk transfer. Reporting entities are financial institutes, including the exposures of foreign offices (i.e. subsidiaries and branches); reported data are on a worldwide-consolidated basis (see BIS (2006)). ${ }^{10}$

Figure 2, top panel, illustrates gross cross-border exposure of BIS-reporting banks, aggregated across the eleven European countries in our sample, by type of debt. It shows that during the height of the financial crisis, the total foreign positions were rewound, in particular those of bank debt. With the onset of the year 2010, the downward trend has continued, but moderately so. The picture is different when focussing on Greek foreign debt to the remaining ten countries (bottom panel). Here, the largest decrease in debt exposure occurred during the year 2010, with positions in sovereign debt dropping the most in absolute terms. ${ }^{11}$

It is important to notice that neither the levels nor the trends in the exposure to Greek debt have not been uniform across all countries. Table 2a shows that within the set of ten European countries, average exposures vary roughly between 0.3 and 2 percent of GDP (for the two years 2009/2010). Table $2 \mathrm{~b}$ reports summary statistics of the evolution of exposure to Greek debt, following the fourth quarter 2009, for which levels are normalized to $100 .^{12}$ Panel A reports numbers for total debt by quarter. The last column thus shows that on average the exposure to Greek debt was $62.6 \%$ of the initial level, while the country that changed exposure least reduced its exposure by $7.4 \%$ (100-92.6) and the severest reduction amounted to 78.8\%. Panel B summarizes exposures for Greek public debt. While up to 2010Q4 the average country reduced the corresponding exposure to $67.8 \%$ of the initial level, the maximum reduction accounted for $83.6 \%$, while one country actually increased exposure by $5 \%$. Finally, panel C reports the numbers based on Greek bank debt. Between

\footnotetext{
${ }^{10}$ BIS (2006) specifies that balance-sheet relevant instruments include "certificates of deposit (CDs), promissory notes and other negotiable paper issued by non-residents, banks' holdings of international notes and coins, foreign trade-related credits, claims under sale and repurchase agreements with non-residents, deposits and balances placed with banks, loans and advances to banks and non-banks, holdings of securities and participations including equity holdings in unconsolidated banks or non-bank subsidiaries."

${ }^{11}$ In principle, the decrease in the exposure to Greek bonds may results from valuation effects. Thus, to grant international comparability, the BIS recommends "that banks' international claims be valued at market prices" but acknowledges that, where "market values are not appropriate, contractual or nominal values should be used." Moreover, differences across countries arise, since "loans in the banking books, which in principle should be assigned nominal value, should be valued in accordance to the reporting countries' accounting standards." (BIS 2006)

${ }^{12}$ The beginning of the Greek sovereign debt crisis can be dated to 2009Q4.
} 
2009Q4 and 2010Q4 the average country reduced exposure to $29.7 \%$ of the initial level, the maximum reduction accounted for as much as $97.8 \%$ and minimum reduction was $3.3 \%$ only. Our aim is to exploit these cross-country differences in time variation to extract information about how sovereign risk is transmitted via the exposure to the different classes of Greek debt.

These data are reported on the immediate borrower basis. While these data are quite comprehensive, the accuracy of effective exposure is a potential source of concern. Unfortunately, availability of data on the ultimate risk basis is very limited. Not only would the use of ultimate borrower basis limit our sample, but Greece would drop out of it. A comparison between the data on the immediate and ultimate basis shows, however, that both measures comove very closely.

Greek Shocks. Coming to the third type of required data, we need to compile a list of those days, where financially relevant news are dominated by information from Greece. For our identification strategy it is essential that we can claim that Greece has been the only origin of a first order shock. Pioneering the "narrative approach," Romer and Romer (1989) stress that potentially severe problems may arise when isolating the shocks due to the judgmental and retrospective nature of the selection process. To reduce the unconscious bias in this selection process, we keep our selection as mechanical as possible. Specifically, we first construct a timeline describing the Euro crisis by merging three sources: Financial Times (Interactive timeline: Greek debt crisis), the Wall Street Journal (Europe's Debt Crisis - Timeline), and Reuters (Europe's Debt Crisis Timelines). ${ }^{13}$ The thus compiled joint timeline covers a period starting with November $5^{\text {th }} 2009$ and ending with November $28^{\text {th }} 2010$ and includes those days that appear to be relevant to the authors of at least one of these timelines. We mechanically extract the days that contain news from Greece. We then limit the resulting list of days by excluding all those days when financially relevant news are reported from countries other than Greece. In addition, we perform a second round of elimination by a search of potential overlapping shocks originating in other countries based on the Lexis-Nexis database. The final list of events comprises 14 information shocks identified as Greek shocks and is reported in Table A1, along with a short description of

\footnotetext{
${ }^{13}$ See http://www.ft.com/intl/cms/s/0/003cbb92-4e2d-11df-b48d-00144feab49a.html\#axzz1eQwHrlj , http://online.wsj.com/article/SB10001424052748704448304575195863350731920.html and http://www.reuters.com/article/2010/08/25/eurozone-crisis-events-idUSLDE67O0YD20100825
} 
the corresponding event.

\section{Empirical Framework}

In this section we discuss our approach to identify sovereign risk spillovers across countries. We start by considering a $n$-dimensional vector autoregressive model

$$
y_{t}=\Phi_{y}(L) y_{t-1}+\Phi_{x} x_{t}+u_{t}
$$

where $y_{t}$ is a vector of CDS spreads for each country, $\Phi_{y}(L)=\sum_{j=1}^{J} \Phi_{y, j} L^{j-1}$ is a polynomial in the lag operator, $x_{t}$ is a $m$-dimensional vector of exogenous variables which includes the constant and $u_{t}$ is a vector of innovations.

In a more compact form, this model can be written as

$$
y_{t}=\Phi z_{t}+u_{t}
$$

where $\Phi=\left[\Phi_{y, 1}, \ldots, \Phi_{y, J}, \Phi_{x}\right]$ is a $n \times p$ matrix and $z_{t}=\left[y_{t-1}^{\prime}, \ldots, y_{t-J}^{\prime}, x_{t}^{\prime}\right]^{\prime}$ is a $p \times 1$ vector, where $p=n J+m$.

Following standard practice we assume that the innovations $u_{t}$ reflect relevant countryspecific information which is instantaneously transmitted across markets according to

$$
u_{t}=B \epsilon_{t}
$$

where $\epsilon_{t}$ denotes a vector of independent and identically distributed shocks with zero mean. The components of $\epsilon_{t}$ can thus be interpreted as the unobservable and idiosyncratic, or "structural", shocks to sovereign risk in each respective country. The matrix $B$, instead, reflects the rate of transmission of these shocks across countries. Without loss of generality, we can normalize the diagonal elements of $B$ to unity by the according choice of units of the shocks.

As part of our identification strategy, we assume that the shock process $\epsilon_{t}$ is characterized by a conditional (signed) mean shift that reflects an exceptional event in each country. Specifically, for each component $i$ we assume

$$
\epsilon_{i, t}=d_{i, t} \xi_{i}+\nu_{i, t}
$$


where $d_{i, t}$ is an indicator function that takes three values, $-1,0$ and $1, \xi_{i}$ is a time-invariant parameter and $\nu_{i, t}$ is identically and independently distributed across time. This notation shall reflect the distinction between the "normal" shocks $\nu_{i, t}$, which affect each country's sovereign risk in every period and are unobservable, and some "abnormal" events that occur rather infrequently and that to some extent are observable. ${ }^{14}$ Applying the same decomposition to each country, we can write

$$
\epsilon_{t}=D_{t} \xi+\nu_{t}
$$

where $D_{t}$ is a diagonal matrix with entries $d_{i, t}$. Assuming that both normal shocks and the occurrence of abnormal events are i.i.d. across countries and time, we can maintain our previous assumption regarding the time invariance and the homoskedasticity of the structural shocks $\epsilon_{t}$.

Pursuing the "narrative approach" of Romer and Romer (1989), we are able to identify the dates in which an exceptional events occurs in Greece but in no other country. Formally, this set of dates $\mathcal{T}^{\text {gr }}$ is

$$
\mathcal{T}^{g r} \equiv\left\{t \mid d_{g r, t} \neq 0 \text { and } d_{i, t}=0 \forall i \neq g r\right\}
$$

In the following we will refer to the elements of $\mathcal{T}^{g r}$ as pure Greek events. On the base of this set of dates, we aim to estimate the response of all other countries to exceptional event in Greece, or equivalently the column of $B$ corresponding to the position of Greece in the vector $y_{t}$. With this objective in mind, we define the signed indicator function as

$$
\mathbf{1}_{g r, t} \equiv \begin{cases}d_{g r, t} & t \in \mathcal{T}^{g r} \\ 0 & t \notin \mathcal{T}^{g r}\end{cases}
$$

so that we can rewrite (3) as

$$
\epsilon_{t}=\mathbf{1}_{g r, t} \xi^{g r}+\left(1-\left|\mathbf{1}_{g r, t}\right|\right) \xi_{t}^{n g r}+\nu_{t}
$$

where $\xi^{g r}$ denotes the vector of exceptional shocks in Greek events, and thus is zero except for its Greek component $\xi_{g r}$, while $\xi_{t}^{n g r} \equiv D_{t \mid t \notin \mathcal{T}{ }^{r r}} \xi$ reflects the random occurrence of exceptional shocks in other countries in all other periods.

\footnotetext{
${ }^{14}$ Despite being quite restrictive, the assumption that the effect of exceptional events is constant over time doesn't affect our results but conveniently reduces notation.
} 
Combining (6) and (2), we can then rewrite our original model (1) as

$$
y_{t}=\Phi z_{t}+\beta \cdot \mathbf{1}_{g r, t}+\tilde{u}_{t}
$$

where $\beta \equiv B \xi^{g r}$ and $\tilde{u}_{t}$ is a modified residual defined as

$$
\begin{aligned}
\tilde{u}_{t} & \equiv \mathbf{1}_{g r, t} u_{t}^{g r}+\left(1-\left|\mathbf{1}_{g r, t}\right|\right) u_{t}^{n g r} \\
u_{t}^{g r} & \equiv B \nu_{t} \\
u_{t}^{n g r} & \equiv B\left(\xi_{t}^{n g r}+\nu_{t}\right) .
\end{aligned}
$$

The residuals $\tilde{u}_{t}$ are conditionally independent of $z_{t}$ and $\mathbf{1}_{g r, t}$ so that we have now a framework that allows us to estimate consistently the components of vector $\beta$, which measure the average response of sovereign risk in each country to a shock in Greece.

In pursuing the approach sketched above, however, we cannot sustain the standard assumption of conditional homoskedasticity in the residuals. By construction, $u_{t}^{g r}$ from (8) depends on the "normal" shocks $\nu_{t}$ only, while $u_{t}^{n g r}$ is the sum of $\nu_{t}$ and, potentially, the "exceptional" shocks $d_{i, t} \xi_{t}^{i}$ in all countries. Our strategy thus forces us to derive an estimator that allows for the presence of two alternating regimes in the variance-covariance matrix of the residuals.

Case 1: Two Regimes of VCV. Writing $\tilde{\Phi}=[\Phi, \beta]$ and $\tilde{z}_{t}=\left[z_{t}^{\prime}, \mathbf{1}_{g r, t}\right]^{\prime}$ we can reformulate model (7) as

$$
y_{t}=\tilde{\Phi} \tilde{z}_{t}+\tilde{u}_{t}
$$

which is formally equivalent to (1). Accounting for heteroskedasticity, we assume that

$$
E_{t}\left(\tilde{u}_{t}\right)=0, \quad E_{t}\left(\tilde{u}_{t} \tilde{u}_{t}^{\prime}\right)=\left\{\begin{array}{ll}
\Sigma_{g r} & \text { if } t \in \mathcal{T}^{g r} \\
\Sigma_{n g r} & \text { otherwise }
\end{array}, \quad E_{t}\left(\tilde{u}_{t} \tilde{u}_{s}^{\prime}\right)=0 \text { for } s \neq t,\right.
$$

where $\mathcal{T}^{g r}$ is the known subset pure Greek events and the two matrices $\Sigma_{g r}$ and $\Sigma_{n g r}$ have full rank and are invertible. We refer to the Appendix for the derivation of a generalized least squares (GLS) estimator of $\tilde{\Phi}$ which accounts for this specific type of heteroskedasticity.

In addition to the arising heteroskedasticity we need to deal with another complication of the narrative approach. Specifically, we cannot infer the rate of cross-country transmission 
of sovereign risk directly from our estimates of $\beta$. By construction, indeed, each component $\beta_{k}$ is a reduced form that depends on the actual rate of transmission from Greece to country $k$, as measured by the component $B_{(k, g r)}$, times the average magnitude of Greek events $\xi^{g r}$. To obviate this problem, we exploit the linearity of our model and we estimate the rate of transmission by looking at the response of each country $k$ relative to the one of Greece, or $\beta_{k} / \beta_{g r}$. The coefficient $\beta_{g r}$ equals $\xi_{t}^{g r}$ so that this ratio captures exactly $B_{(k, g r)}$. We then compute a confidence interval for each of these ratios by bootstrapping the residuals from regression. ${ }^{15}$

Coming back to our goal of assessing the role of financial linkages in the spreading of the current European sovereign crisis, we recognize that the literature has identified alternative transmission channels, which range from the cross-country linkages of the real economy such as trade relations and technological spillovers to non-fundamental-based linkages. We observe, however, that financial exposure tends to move much faster than real bilateral linkages and its evolution is not directly linked to changes in market sentiments. We therefore exploit the time variation in order to identify the contribution of financial linkages to the overall transmission of sovereign risk. Specifically, we allow the spillover matrix $B$ in (2) to vary over time and we decompose it into a time-invariant component and a time-varying component, the latter being a function of our measure of financial linkages.

Such a decomposition requires a modification of model (7) where we allow the transmission matrix $B_{q}$ to vary across quarters $q .{ }^{16}$ We then assume that the cross-country spillovers are linear in the financial linkages, imposing on $B_{q}$ the following form

$$
B_{q}=B_{0}+d L_{q}
$$

where $B_{0}$ is a constant matrix capturing the time-invariant channels and the components of $L_{q}$ are our measures of financial linkages, which vary across quarters. In (10) we maintain our previous normalization and we set all diagonal entries of $B_{0}$ to one (the diagonal entries of $L_{q}$ are zero by construction). Furthermore, $d$ is a scalar, indicating that financial linkages transmit sovereign risk from one country to another in the same way, i.e. independently of

\footnotetext{
${ }^{15}$ In doing so, we take special care of resampling the residuals only within each variance-covariance regime but not across them to satisfy the assumption of invariance in distribution that underlies the bootstrapping technique.

${ }^{16}$ The choice of quarters as the frequency of variation of the transmission matrix $B$ is based on the availability of data for our measure of financial linkages.
} 
the country pair.

Our main goal is to estimate the scalar $d$ in (10). To do so, we consider the following specification of the model

$$
y_{t}=\Phi z_{t}+\left(\delta_{0}+\delta_{1} l_{g r, q}\right) \cdot \mathbf{1}_{g r, t}+\tilde{u}_{t}
$$

where $\delta_{0} \equiv\left(I+B_{0}\right) \xi^{g r}$ is a $n \times 1$ vector, $\delta_{1} \equiv d \cdot \xi_{g r}$ is a scalar and $l_{g r, q}$ is a $n \times 1$ vector of cross-border financial exposures to Greece.

The key parameter $d$ is assumed to be constant across all country pairs, which constitutes a restriction on the estimated coefficients. Technically, this requires to impose a cross-equation restriction on the interaction coefficient appearing in the above specification. Furthermore, implicit in model (11) is the fact that the residual $\tilde{u}_{t}$ now depends on $B_{q}$ (see (8)), and thus has a variance-covariance matrix which can vary both across regimes (Greek and non-Greek) and the quarters $q$. We thus need to derive an estimator that allows us to deal with these properties of the model.

Case 2: Restricted Regressors and $N$ Regimes of VCV. Consider the following model

$$
y_{t}=\tilde{\Phi} \tilde{z}_{t}+\tilde{u}_{t} \quad \tilde{\Phi}_{(k)}^{\prime}=R_{k} \cdot c_{k}
$$

for $k=1, \ldots, n$. Here $\tilde{\Phi}=\left[\Phi, \delta_{0}, \Delta_{1}\right], \tilde{z}_{t}=\left[z_{t}^{\prime}, \mathbf{1}_{g r, t}, l_{g r, q}^{\prime} \cdot \mathbf{1}_{g r, t}\right]^{\prime}$. Thus, $\Delta_{1}$ denotes a vector of coefficients on the interaction term $l_{g r, q} \cdot \mathbf{1}_{g r, t}$. The equation on the right specifies a set of linear restrictions on each row $\tilde{\Phi}_{(k)}$ of the matrix of coefficients $\tilde{\Phi}$. Imposing

$$
R_{k}=\left(\begin{array}{ccc}
I_{p \times p} & 0_{p \times 1} & 0_{p \times 1} \\
0_{1 \times p} & 1 & 0 \\
0_{n \times p} & 0_{n \times 1} & e^{k}
\end{array}\right) \quad \text { and } \quad c_{k}=\left[\Phi_{(k)}, \delta_{0, k}, \delta_{1}\right]^{\prime}
$$

where $e^{k}$ is the $k^{t h}$ unit vector of length $n$, this model is identical to our specification (11).

The residual process satisfies the following set of assumptions

$$
E_{t}\left(\tilde{u}_{t}\right)=0, \quad E_{t}\left(\tilde{u}_{t} \tilde{u}_{t}^{\prime}\right)=\left\{\begin{array}{ll}
\Sigma_{g r, q} & \text { if } t \in \mathcal{T}_{q} \cap \mathcal{T}^{g r} \\
\Sigma_{n g r, q} & \text { if } t \in \mathcal{T}_{q} \backslash \mathcal{T}^{g r}
\end{array}, \quad E_{t}\left(\tilde{u}_{t} \tilde{u}_{s}^{\prime}\right)=0 \text { for } s \neq t,\right.
$$

where $\mathcal{T}_{q}$ is the set of dates in quarter $q$ and $\mathcal{T}^{g r}$ as defined in (4). This formulation allows the variance-covariance matrix of residuals to depend on the quarter $q$ within the two regimes. 
We refer once again to the Appendix for a technical description of the restricted GLS estimator we use to estimate model (12) under the specific type of heteroskedasticity assumed in $(13)$.

We are now ready to perform our estimations. Specifically, in a two-step procedure, we would first estimate (11) by simple OLS, compute the residuals to obtain estimates for the quarter-specific VCV matrices $\Sigma_{n g r, q}$ and $\Sigma_{g r, q}$ and then use these matrices to estimate the feasible GLS. The value of $d$ can then be inferred by normalizing the estimate of $\delta_{1}$ by the average size of Greek events which, by our normalization of $B_{0}$, corresponds to the Greek component of $\delta_{0}$. We then construct the confidence interval by repeating the two-step estimation procedure with bootstrapped residuals in order to obtain a synthetic distribution for the estimate of $d$.

Proceeding on this route, however, we face the difficulty that the quarterly sets of dates with Greek events, $\mathcal{T}_{q}$, contain, on average, less than two elements. Thus, the standard estimate of the quarter-specific variance-covariance matrix

$$
\hat{\Sigma}_{g r, q}=\frac{1}{\left|\mathcal{T}_{q} \cap \mathcal{T}^{g r}\right|} \sum_{t \in \mathcal{T}_{q} \cap \mathcal{T}^{g r}} \tilde{u}_{t} \tilde{u}_{t}^{\prime}
$$

delivers matrices that do not have full rank and cannot be inverted for the calculation of the GLS estimations. We deal with this problem by simply taking the time-average variance-covariance matrix for all quarters.

\section{Results}

This section summarizes the results of the generalized least square (GLS) estimations of the transmission of sovereign risk. We begin by estimating model (7) to assess average, time-invariant transmission. We then turn to model (11) to analyze the role of the financial linkages.

Unless explicitly described otherwise, the dependent vector $y_{t}$ consists of five-year sovereign CDS of eleven European countries (including Greece), logged and differentiated. ${ }^{17}$ We $\log$ the data in order not to give excessive weight to the relatively large reactions of 'PIGS' or other troubled countries (compare Figure 1). Intuitively, a jump of Danish CDS

\footnotetext{
${ }^{17}$ We differentiate the CDSs to make them stationary. The estimation results remain intact for HPfiltered data.
} 
from 30 to 50 basis points should be considered much more dramatic than an increase of Portuguese CDS from 450 to 470 basis points. The vector of independent variables $\tilde{z}_{t}$ comprises the lags of $y_{t}$, exogenous variables $x_{t}$, the Greek dummy and, when estimating model (11), the interaction of the Greek dummy with a measure of financial exposure to Greece. To control for common shocks affecting global market conditions, the vector of exogenous variables consists of the following variables: sovereign CDS of the U.S. and of Japan (logged and differentiated as all other CDS and lagged), the U.S. VIX (logged and lagged), market returns (defined as log changes of the S\&P index), the U.S. federal fund rate, and seasonal dummies for each day of the week.

The data are reported on a daily basis, except those of the financial linkages. They span a period of 522 business days for the calender years 2009 ad $2010 .{ }^{18}$

\subsection{Baseline Specification - Time Invariant Transmission}

In our baseline specification we estimate model (7). The coefficient $\beta$ is constant over the entire period and thus captures the time-average of the response to the identified Greek shocks by the ten other European countries.

Our tests of autocorrelation of the residuals prompt us to include eight lags of the dependent variable and no lag of the exogenous variables. Moreover, we disregard heteroskedasticity within the set of days where Greek events occur.

Table 3a, reports the results for the baseline specification. The columns correspond to the elements of the vector $y_{t}$, i.e. to the eleven countries. In the upper panel, we report the corresponding coefficients on the indicator for Greek events $(G R)$, along with the standard errors. All of the estimates of the eleven coefficients are positive and the implied t-ratios indicate that most of the coefficients are statistically significant at least on the five percent level. The exceptions are those corresponding to Germany and the Netherlands. The point estimate for Greece itself is 0.0722, which indicates that the events identified in Table A1 generated, on average, a jump in the Greek sovereign CDS of over 7 percent. At a timeaverage of 679 basis points in 2010, this average change of CDS is roughly equivalent to a jump of 49 basis points $(679 * .0722=49.024)$.

\footnotetext{
${ }^{18}$ The eleven countries are Austria, Belgium, France, Germany, Great Britain, Greece, Italy, Netherlands, Portugal, Spain and Sweden. Finland, Denmark and Iceland drop out of the sample becasue of limitated data coverage.
} 
The coefficients corresponding to countries other than Greece itself vary from 0.0113 (Netherlands) to 0.0310 (Italy). Measured relative to the magnitude of the Greek one (lower panel), these estimates imply a rate of transmission that ranges from $15.6 \%$ and $42.9 \%$, with an average for all ten countries equal to $32.0 \% .{ }^{19}$ These numbers indicate economically important transmission rates. At the same time, the estimated coefficients are strikingly similar in magnitudes. To put this observation into perspective, recall that the CDSs are logged so that the coefficients measure the transmission of Greek shocks in percent of the countries' sovereign CDS. Thus, a one percent increase in the Portuguese CDS corresponds to a jump of 2.9 basis points, while one percent increase in French CDS corresponds to an increase of 0.7 basis points, based on 2010 averages.

Assessing transmission rates in levels, Table $3 \mathrm{~b}$ repeats the estimates without prior logging the CDS0. Again, all estimates are positive, while significance drops for Austria and Belgium now. The coefficient for Greece indicates an average jump of 37.78 basis points in Greek events, somewhat lower but in the same realm of the benchmark computed through the elasticities. The response of European sovereign CDS relative to the Greek one ranges at lower levels, between $0.98 \%$ and $22.52 \%$.

Figure 3 plots the impulse response functions for all eleven countries, including the 5 percent confidence bounds. The figure shows that a Greek shock generates a positive contemporaneous response in all countries, which is significant in most of them. The significant positive impact tends to persist for one day but vanishes thereafter. More importantly, the figure shows no negative amplitude in the days following the Greek shock, which indicates that the responses to a Greek shock is not transitory and the sovereign CDS do not revert to their initial level after a while. ${ }^{20}$

Overall, the results from the baseline regression indicate that there are substantial rates of transmission of sovereign risk across Europe. In the next step, we analyze the role of financial linkages for that transmission.

\footnotetext{
${ }^{19}$ Notice that there is a strong relation in the statistical significance of normalized and absolute responses. The only exceptions are Italy and Spain, where we observe a slight loss of significance. We attribute this difference to the use of bootstrap confidence intervals in the case of normalized response.

${ }^{20}$ The confidence bounds are derived from a bootstrap distribution based on 1000 replications.
} 
Figure 3: Impulse Response Functions
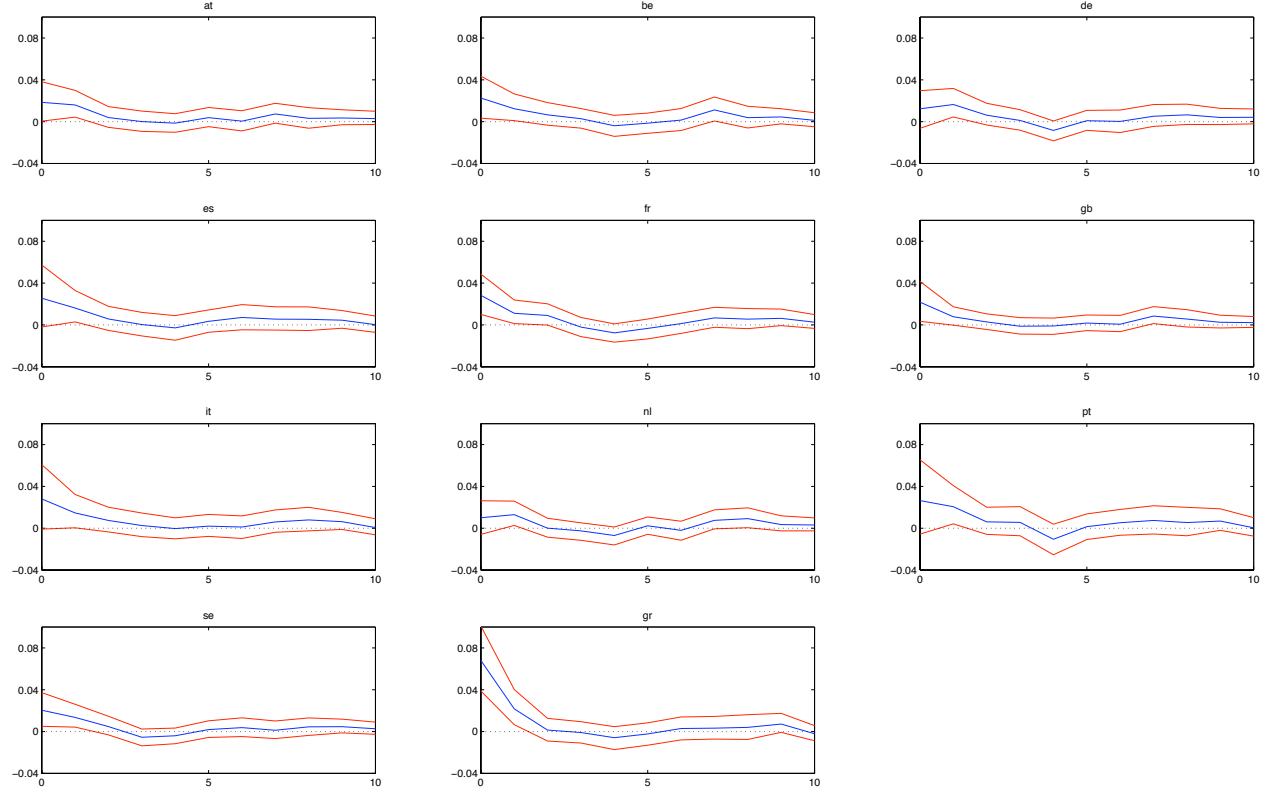

Impulse response functions of CDS (log-changes) of eleven countries to a Greek shock of average size for the 20 business days after impact (blue line). The red lines indicate the $5 \%$ confidence bounds based on bootstrap exercise with 1000 replications.

\subsection{Financial Linkages}

We turn now to the estimation specified in (11) in order to analyze the role of financial linkages in the Euro crisis, exploiting the time-variation of the exposure to Greek debt. We use three measures for the linkages: the exposure (i) to total Greek debt, (ii) to Greek public debt and (iii) to debt of Greek banks. All measures are normalized by average real GDP of the years 2009 and 2010 and logged. Whenever there is no risk of confusion, we will refer to these measures as the exposure to Greece.

Table 4 reports the estimation results based on model (11). Column I corresponds to the specification that relies on the exposures to Greece defined through Total Greek debt. The first row of the table reports the coefficients on the Greek dummy $(G R)$, measuring the Greek fixed effect of the average Greek shock. The coefficient is 0.0737 , close to the point estimate in our baseline regression (Table 3a). In our analysis of the role of financial linkages for the transmission of sovereign risk, the coefficient of interest is the one on $G R *$ Total, i.e. the interaction term between the Greek dummy and the exposure to Greece $\left(l_{g r, q} \cdot \mathbf{1}_{g r, t}\right.$ 
in (11)). This estimated coefficient is positive and significant at the one percent level, as indicated by the implied t-ratios.

To assess the transmission independent of the size of the original shock, the coefficient on $G R *$ Total needs to be normalized by the average size of the Greek shock. Since we cannot observe the magnitude of the underlying shock, we normalize the coefficient on $G R *$ Total by the Greek component of the Greek dummy $(G R)$. The resulting ratio measures how the exposure to Greece impacts the transmission rate of sovereign debt. For brevity, we will refer to this measure as Exposure. The point estimates in Column I result in a value of 0.2809 for Exposure. As discussed in the Section 3, we cannot derive a theoretical distribution for Exposure and resume to bootstrapping to assess statistical significance. The lower part of Table 4 summarizes the bootstrap confidence bounds based on 1000 bootstrap replications, indicating that the one percent confidence interval is on the positive axis. Based on a one percent confidence level, we can thus conclude that the bilateral exposure to Greek debt plays a positive role for the transmission of sovereign risk. The exposure to Greek debt is not only statistically significant but also economically relevant: the value of 0.2809 for Exposure indicates that a one percent reduction in the exposure to Greece decreases a country's CDS response to a Greek shock by almost a third of a percent. Based on a rough calculation, the relative response of sovereign default risk of other European countries due to a Greek shock would have been 28 percent smaller in absence of any financial exposure. We take these indicative results as a motivation to scrutinize the different sub-components of Total Greek debt, i.e. Greek public debt and the debt of Greek banks.

Column II corresponds to the specification where exposure to Greece is defined through Greek public debt. The coefficient on the dummy $G R$ is 0.0737 , the one on interaction term $G R *$ Public equals 0.0207. The implied t-ratios of both coefficients indicate significance at the 1 percent level. The ratio of the two point estimates in Column I results in a value of 0.189 for Exposure. The lower part of Column II shows that the bootstrap confidence interval for the one-percent confidence level is on the positive axis. In addition, value of Exposure lies well in the middle of these intervals and is close to the mean of the sample of bootstrap replications (mean BStr), reported to be 0.2088. Figure 4 illustrates the bootstrap distribution for the Exposure, the coefficient indicating the transmission 
through financial linkages.

The value of 0.189 for Exposure exposure to Greek sovereign debt indicates that a one percent reduction in this exposure decreases a country's CDS response to a Greek shock by almost a fifth of a percent. A rough calculation indicates that the relative response of sovereign default risk of other European countries to a Greek shock would have been 19 percent smaller in absence of any financial exposure. Combining this information with the average rate of transmission of $30.0 \%$ (compare Section 4.1), our results indicate that about two thirds of the transmission of sovereign debt in the Euro Crisis has operated through financial channels.

For a more concrete example, consider the increase from 124.6 to 1026.5 basis points in Greek CDS between October $1^{\text {st }} 2009$ and December $31^{\text {st }}$ 2010. Assuming half of that increase can be attributed to innovations of Greek origin, then the rise in Germany CDS would have been 11.2 basis points lower, while the rise of Portuguese and Spanish would have been 57.2 and 81.6 basis points lower, respectively, explaining about $63.4 \%, 43.1 \%$ and $38.7 \%$ of the increases in CDS in these three countries. ${ }^{21}$

Figure 4: Bootstrap Distribution of the Rate of Response to Greek News

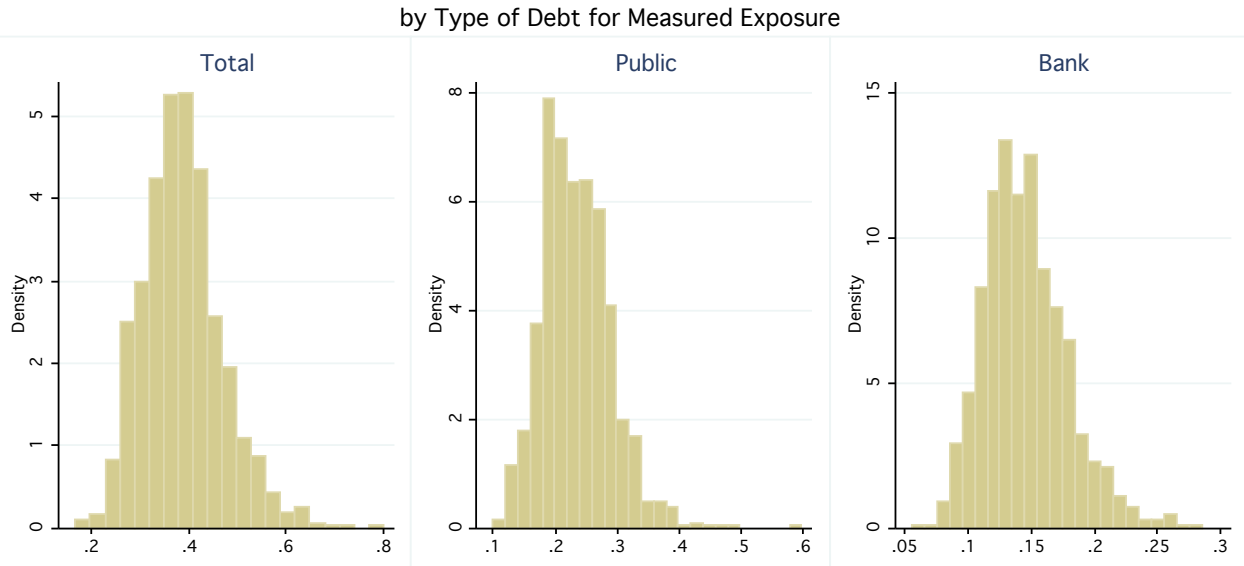

Distribution of the estimated parameter of the rate of response ( $d$ in Tables 3-8), derived from 1000 bootstrap replications. The panels correspond to the financial exposure to Greek public, bank and non-bank private debt.

Column III of Table 4 reports parallel results when exposure to Greece is measured

\footnotetext{
${ }^{21}$ Excluding Sweden, for which the CDS actually dropped in this period, the sample average of the explained increase is $71 \%$.
} 
through Bank debt. Again, the coefficient on the interaction term $G R *$ Bank is positive and significant on the one percent level, and the implied value for Exposure is 0.118. The bootstrap confidence bounds indicate that the Exposure is significant at the one percent level. The magnitude of the point estimates suggest that the role of exposure to debt of foreign bank is somewhat less important for the transmission of sovereign debt: the elasticity of the spillover effects to bank debt exposure is measured to be about two thirds of the corresponding elasticity with respect to direct exposure to Greek sovereign debt.

The value of 0.118 for Exposure exposure to debt of Greek banks indicates that a one percent reduction in this exposure decreases a country's CDS response to a Greek shock by almost a 0.12 percent. Again, in a rough calculation, the relative response of sovereign default risk of other European countries due to a Greek shock would have been 12 percent smaller in absence of any financial exposure.

Overall, the baseline estimates suggest that the rates of exposure to Greek sovereign debt and to debt of Greek banks played an important role for the spreading of sovereign risk across the Euro area. Interestingly, our estimate of elasticity regarding total exposure (0.2809) appears to linearly decompose into one third stemming from exposure to Greek banks (0.118) and two thirds stemming from exposure to Greek sovereign debt (0.189). ${ }^{22}$

\subsection{Robustness}

We conduct a number of robustness checks. First, we repeat our estimations, measuring CDS in basis points and the exposure to Greek debt in percent of GDP (i.e., we do not $\log$ these variables). In this linear specification, the CDS of the European countries is assumed to react to a Greek shock independently of their actual level. An increase of Danish CDS from 30 to 50 basis points is thus treated similar as an increase of Portuguese CDS from 450 to 470. Moreover, an increase of GDP-normalized exposure from 0.01 to 0.02 is assumed to have the same effect as an increase from 0.11 to 0.12 exposure per GDP. This specification therefore puts less weight on the time variation of very lightly exposed countries. Table 5 shows that all signs of the estimates are preserved under this linear specification. However, Column I indicates the coefficient of the interaction term

\footnotetext{
${ }^{22}$ It is clear that this calculation is overly simplifying, since the elasticity of variable $y$ to $x$ do not linearly decompose into the elasticities of $y$ to the subcomponents of $x$.
} 
$G R *$ Total ceases to be significant, which translates into an insignificant relative response Exposure, as the bootstrap confidence bounds show. For the specifications involving Greek Public debt and debt of Greek banks, however, the estimates are intact and significant on the one percent level. The estimates of the coefficient $d$ are 5.91 and 22.53, respectively. With these point estimates, based on exposure in percent of GDP, we can give the following absolute interpretation of our results. The value for the relative response of 22.53 suggests that a reduction of exposure to debt of Greek banks of 0.1 percent of GDP (the average exposure is 0.17 percent of GDP) implies that the relative response decreases by almost a quarter $(0.01 * 22.5=0.225)$. Just as the estimates with the logged variables, these numbers indicate large transmission rates and a prominent role of financial linkages for the transmission of sovereign debt.

Next, we limit the number of countries in our sample. Specifically, we observe that Belgium, the Netherlands and Sweden exhibit exceptionally large changes of the financial linkages for these countries (in percent). To make sure that previous results are not driven by a few of these extreme changes, we replicate our estimations, excluding the three countries from our sample. The results are reported in Table 6. The estimates of Exposure for the specification with Public and Bank debt with the limited sample are roughly double in magnitude compared to the ones in the full sample (compare Table 4), while the high significance levels are preserved. Thus, the numbers suggest that a 100 percent reduction in the exposure to Greece decreases a country's CDS response to a Greek shock by almost half $(-1 * 0.48=-0.48)$. Overall, the qualitative results of our baseline specification seem not to be driven by a small number of countries with the largest time-variation in the exposure of to Greek debt.

As a third robustness check, we exclude Sweden and UK from our sample, which limits the analysis to countries within the Euro zone. We thus include only the countries, which assume implicit liabilities through the ECB balance sheet. A comparison between results of this reduced and the full sample are therefore indicative whether the transmission of sovereign risk operates significantly through ECB assets, in which case the Exposure should be estimated to be larger for the reduced sample. Table 7 shows that the relative response, Exposure, is significant on the one percent level for all specifications. Moreover, for the reduced sample, all three estimates of Exposure are very close to but somewhat lower 
than those of the full sample (compare Table 4) and the respective ten percent confidence intervals overlap widely. These results do not indicate strong transmission channels via the ECB balance sheet.

Finally, we try to capture not only the spillover effects of direct exposure to Greek debt but the entire network of financial linkages across European continent. In particular, if French banks are strongly exposed to Greek sovereign debt, while Spanish banks are not, the Spanish banks might nevertheless suffer from an increase in Greek sovereign risk due to their indirect exposure through the French banking system. To capture these indirect effects, we invert the matrix of bilateral financial linkages and estimate the corresponding Greek column of the matrix of financial linkages. The exposure now captures the overall i.e., the direct and the indirect - transmission of Greek shocks to the respective European countries. Table 8shows that our estimates are intact, except for the fact that under the specification with Bank Debt, Exposure is now significant on the five percent level only (Column III).

\section{Conclusion}

This paper has shown that financial linkages did matter for the transmission of sovereign risk in the Euro crisis. Our estimates show that a 10 percent increase in the exposure to foreign sovereign debt increases the spillover effects of sovereign risk by 1.8 percent. Similarly, a 10 percent increase of exposure to debt of foreign banks, increases these spillover effects by 1.2 percent. These estimates are statistically significant and economically relevant.

Methodologically, we follow the narrative approach by Romer and Romer (1989), identifying financially relevant news shocks that can be attributed to Greek's problems to service its sovereign debt. These shocks are then used to assess the response of sovereign risk of other European countries. We further relate the latter responses to cross-border financial linkages, controlling for transmission channels that are slow to change through fixed effects. 


\section{References}

Acharya, Viral V., Itamar Drechsler and Philipp Schnabl 2011: " A Pyrrhic Victory? Bank bailouts and Sovereign Default Risk" NBER WP 17136

Arezki, Rabah, Bertrand Candelon and Amadou Sy 2011: "Sovereign Rating News and Financial Markets Spillovers: Evidence from the European Debt Crisis" CESIFO WP 3411

Bank for International Settlement 2006: "Guidelines to the international consolidated banking statistics," www.bis.org

Bank for International Settlement 2011: "OTC derivatives market activity in the second half of 2010," www.bis.org

Baldwin, Richard and Daniel Gros 2010: "The euro in crisis - What to do?" in "Completing the Eurozone Rescue: What More Needs to be Done?" eds: Richard Baldwin, Daniel Gros and Luc Laeven

Barkleys Capital: "Standard Corporate CDS Handbook. Ongoing Evolution in the CDS Market," February 2010

Benati, Luca and Paolo Surico, 2009: "VAR Analysis and the Great Moderation," American Economic Review, Vol. 99 (4), pp. 1636-52.

Blundell-Wignall, A. and P. Slovik 2010: "The EU Stress Test and Sovereign Debt Exposures", OECD Working Papers on Finance, Insurance and Private Pensions, No. 4, OECD Financial Affairs Division, www.oecd.org/daf/fin

Bhanot, K., N. Burns, D. Hunter, and M. Williams 2011: "Comovement and Contagion among PIIGS' Sovereign Bonds: The Impact of News Announcements and Risk Perceptions" mimeo, University of Texas at San Antonio

"Was there Contagion in Eurozone Sovereign Bond Marketsduring the Greek Debt Crisis?"

Bolton, Patrick and Olivier Jeanne 2011: "Sovereign Default Risk and Bank Fragility in Financially Integrated Economies," NBER WP 16899

Chan-Lau, Jorge A. 2010: "Balance Sheet Network Analysis of Too-Connected-to-Fail Risk in Global and Domestic Banking Systems" IMF WP/10/107 
Degryse, H., M. A. Elahi, and M. F. Penas 2010: "Cross-border Exposures and Financial Contagion," International Review of Finance 10:2,, pp. 209-240.

Dieckmann, Stephan and Thomas Plank 2010: "Default Risk of Advanced Economies: An Empirical Analysis of Credit Default Swaps during the Financial Crisis" mimeo University of Pennsylvania

Favero, C.A. and Giavazzi, F. 2002: "Is the International Propagation of Financial Shocks Non Linear? Evidence from the ERM," Journal of International Economics, Vol. 57(1), pp. 231-246.

Favero Carlo and Francesco Giavazzi 2007: Debt and the Effects of Fiscal Policy," NBER WP 12822

Fontana, Alessandro and Martin Scheicher 2010: "An analysis of euro area sovereign CDS and their relation with government bonds," ECB WP 1271

Forbes Kristin J. and Menzie D. Chinn 2004: "A Decomposition of Global Linkages in Financial Markets over Time," The Review of Economics and Statistics, Vol 86(3): pp. 705-722

Forbes, Kristin J. and Roberto Rigobon 2002: "No Contagion, Only Interdependence: Measuring Stock Market Co-movements," Journal of Finance, Vol. 57 (5), pp. 2,223-2,261.

Hamilton, James D. 1994: "Time Series Analysis," Princeton University Press, Princeton, NJ

Hilscher, Jens and Yves Nosbusch 2010: "Determinants of Sovereign Risk: Macroeconomic Fundamentals and the Pricing of Sovereign Debt," Review of Finance Vol. 14, pp. 235-262

Hoover, Kevin D. and Stephen J. Perez 1995 "Post hoc ergo propter once more an evaluation of 'does monetary policy matter?' in the spirit of James Tobin," Journal of Monetary Economics, Vol. 34 (1), pp. 47-74

Hui, Cho-Hoi and Tsz-Kin Chung 2011: "Crash risk of the euro in the sovereign debt crisis of 2009-2010" Journal of Banking and Finance, Vol 35, pp. 2945-2955

Joriona, Philippe and Gaiyan Zhang 2007: "Good and bad credit contagion: Evidence from credit default swaps," Journal of Financial Economics Vol. 84, pp. 860-883 
Kallestrup, René, David Lando and Agatha Murgoci 2011: "Financial sector linkages and the dynamics of bank and sovereign credit spreads" mimeo Copenhagen Business School

Leeper, Eric M. 1997: "Narrative and VAR Approaches to Monetary Policy: Common Identification Problems," Journal of Monetary Economics, Vol. 40, pp. 641-657

Packer, Frank and Chamaree Suthiphongchai 2003: "Sovereign credit default swaps," BIS Quarterly Review

Pan, Jun and Kenneth J. Singleton 2008: "Default and Recovery Implicit in the Term Structure of Sovereign CDS Spreads," Journal of Finance

Ramey, Valerie A. 2011: "Identifying Government Spending Shocks: It's all in the Timing," Quarterly Journal of Economics, Vol. 126 (1) pp. 1-50.

Ramey, Valerie A. and Matthew Shapiro 1998: "Costly Capital Reallocation and the Effects of Government Spending," Carnegie Rochester Conference on Public Policy, 48(1): 14594.

Roberto Rigobon, 2003: "Identification Through Heteroskedasticity," The Review of Economics and Statistics, 85(4), 777-792.

Romer, Christina D and David H. Romer 1989: "Does monetary policy matter? A new test in the spirit of Friedman and Schwartz," NBER Macroeconomics Annual 1989, Volume 4

Romer, Christina D and David H. Romer 1997: "Identification and the narrative approach: A reply to Leeper," Journal of Monetary Economics Vol. 40, pp. 659-665

Romer, Christina D and David H. Romer 2004: ÒA New Measure of Monetary Shocks: Derivation and Implications,Ó American Economic Review, 94(4): 105584.

Romer, Christina D and David H. Romer 2010: "The Macroeconomic Effects of Tax Changes: Estimates Based on a New Measure of Fiscal Shocks," American Economic Review, 100 (2010), 763-801.

Sgherri, Silvia and Edda Zoli 2009: "Euro Area Sovereign Risk During the Crisis" IMF $\mathrm{WP} / 09 / 222$

Silvia Sgherri and Edda Zoli 2009: "Euro Area Sovereign Risk During the Crisis," IMF Working Paper 
Stulz, René M. 2010: "Credit Default Swaps and the Credit Crisis,"NBER WP 15384

Sy, A. N. R. 2009, "The Systemic Regulation of Credit Rating Agencies and Rated Markets," World Economics, vol. 10(4), pp. 69-108, October.

Thorbecke, Willem 1997: "On Stock Market Returns and Monetary Policy," The Journal of Finance, Vol. 52 (2), pp. 635-654 


\section{A The Estimator}

We derive the estimator used in main body of the paper. To do so, we will proceed in several steps. First, we state a technical result on matrix inversion, which we use later. Second, we derive a multi-variate generalized least squares (GLS) estimator under the type of heteroskedasticity described in the main text. Third, we describe our bootstrapping techniques.

\section{A.1 Matrix Algebra}

Claim 1 Let $\Sigma_{k}$ be a collection of $n \times n$ matrices with full rank, for $k=1, \ldots, K$. Let further $I_{k}$ denote $m \times m$ matrices of the following form: all off-diagonal elements equal to zero, all diagonal elements are either zero or one and the $I_{k}$ sum to the unit matrix: $\sum_{k} I_{k}=\mathbf{1}_{m}$. Then,

$$
\left(\sum_{k=1}^{K} \Sigma_{k} \otimes I_{k}\right)^{-1}=\sum_{k=1}^{K} \Sigma_{k}^{-1} \otimes I_{k}
$$

holds, where $\otimes$ symbolizes the Kronecker matrix multiplication.

Proof. Multiplication of $\sum_{k} \Sigma_{k} \otimes I_{k}$ and the right hand side in (14) and exploiting the basic properties of the Kronecker multiplication yields

$$
\begin{aligned}
\left(\sum_{k} \Sigma_{k} \otimes I_{k}\right) \sum_{k} \Sigma_{k}^{-1} \otimes I_{k} & =\sum_{k}\left(\Sigma_{k} \otimes I_{k}\right)\left(\Sigma_{k}^{-1} \otimes I_{k}\right)+\sum_{k \neq j}\left(\Sigma_{k} \otimes I_{k}\right)\left(\Sigma_{j}^{-1} \otimes I_{j}\right) \\
& =\sum_{k} \Sigma_{k} \Sigma_{k}^{-1} \otimes I_{k} I_{k}+\sum_{k \neq j} \Sigma_{k} \Sigma_{j}^{-1} \otimes I_{k} I_{j} \\
& =\sum_{k} \mathbf{1}_{n} \otimes I_{k}+\sum_{k \neq j} \Sigma_{k} \Sigma_{j}^{-1} \otimes \mathbf{0}_{m} \\
& =\mathbf{1}_{n} \otimes \sum_{k} I_{k}=\mathbf{1}_{n m}
\end{aligned}
$$

\section{A.2 GLS Estimator - Two Regimes of VCV-Matrix}

Consider the $n$-dimensional model

$$
y_{t}=\tilde{\Phi} \tilde{z}_{t}+\tilde{u}_{t},
$$


where $\tilde{\Phi}=[\Phi ; \beta]$ and $\tilde{z}_{t}=\left[z_{t}^{\prime} ; \mathbf{1}_{g r, t}\right]^{\prime}$. The residuals $\tilde{u}_{t}$ satisfy

$$
E_{t}\left(\tilde{u}_{t}\right)=0, \quad E_{t}\left(\tilde{u}_{t} \tilde{u}_{t}^{\prime}\right)=\left\{\begin{array}{ll}
\Sigma_{g r} & \text { if } t \in \mathcal{T}^{g r} \\
\Sigma_{n g r} & \text { if } t \notin \mathcal{T}^{g r}
\end{array}, \quad E_{t}\left(\tilde{u}_{t} \tilde{u}_{s}^{\prime}\right)=0 \text { for } s \neq t\right.
$$

where $\mathcal{T}^{g r}$ is the set of greek events and $\Sigma_{g r}$ and $\Sigma_{n g r}$ are assumed to be non-singular. Here and in the following, $E_{t}$ denotes the expected value given the information set available at period $t$.

Further assumptions are required, in particular, to guarantee the asymptotic normality of the GLS estimator. Following Lütkepohl (2007, p. 397), we assume throughout that the residual $\tilde{u}_{t}$ is a white noise process, the matrix $\tilde{\Phi}$ of autoregressive coefficients satisfies a stability condition, and that the vector of exogenous variables $x_{t}$, which appears among the elements of $z_{t}$, is generated by a stationary, stable VAR process which is independent of the process $\tilde{u}_{t}$.

For a sample size $T$, model (15) can be written compactly as

$$
\mathbf{y}=\left(I_{n} \otimes \tilde{Z}^{\prime}\right) \tilde{\boldsymbol{\phi}}+\tilde{\mathbf{u}}
$$

where $\mathbf{y}$ is the $n T \times 1$ vector obtained by stacking the $T$-dimensional vectors $y_{(k)}$ formed by the time series of each $k^{\text {th }}$ component of $y_{t}, \tilde{\mathbf{u}}$ is similarly defined by stacking the vectors $u_{(k)}$ formed by the time series of the components of $\tilde{u}_{t}, I_{n}$ is a $n$-dimensional identity matrix and $\tilde{Z}=\left[\tilde{z}_{1}, \ldots, \tilde{z}_{T}\right]$ is the $(p+1) \times T$ matrix formed by the time series of vector $\tilde{z}_{t}$. Here, $p+1$ denotes the number of regressors in each equation of model (15), which include $p=n J+m$ variables plus the Greek dummy. $\tilde{\phi}=\left[\tilde{\Phi}_{(1)}^{\prime}, \tilde{\Phi}_{(2)}^{\prime}, \ldots, \tilde{\Phi}_{(n)}^{\prime}\right]^{\prime}$ is the $n(p+1) \times 1$ vector obtained from stacking the rows $\tilde{\Phi}_{(k)}$ of matrix $\tilde{\Phi}$.

Consistently with the assumptions in (16), the variance-covariance of the vector of residuals $\tilde{u}_{t}$ satisfies

$$
\Sigma_{\tilde{\mathbf{u}}}=\Sigma_{g r} \otimes I_{T}^{g r}+\Sigma_{n g r} \otimes I_{T}^{n g r} .
$$

Here $I_{T}^{g r}$ is a $T$-dimensional diagonal matrix whose diagonal entries corresponds to the entries of the vector $\left[\mathbf{1}_{g r, 1}, \ldots, \mathbf{1}_{g r, T}\right]$ and $I_{T}^{n g r}=I_{T}-I_{T}^{g r}$. The GLS estimator of $\tilde{\boldsymbol{\phi}}$ thus minimizes $\tilde{\mathbf{u}}^{\prime}\left(\Sigma_{\tilde{\mathbf{u}}}\right)^{-1} \tilde{\mathbf{u}}$ and equals

$$
\widehat{\tilde{\boldsymbol{\phi}}}=\left[\left(I_{n} \otimes \tilde{Z}\right) \Sigma_{\tilde{\mathbf{u}}}^{-1}\left(I_{n} \otimes \tilde{Z}^{\prime}\right)\right]^{-1}\left(I_{n} \otimes \tilde{Z}\right) \Sigma_{\tilde{\mathbf{u}}}^{-1} \mathbf{y}
$$

Under the assumption in (16) and the regularity conditions discussed above, we can show 
Claim 2 The GLS estimator of $\tilde{\beta}$ converges in distribution according to

$$
\sqrt{T}(\widehat{\tilde{\boldsymbol{\phi}}}-\tilde{\boldsymbol{\phi}}) \stackrel{d}{\rightarrow} N\left(\mathbf{0}, \mathcal{Q}^{-1} \mathcal{V} \mathcal{Q}^{-1}\right)
$$

where $\mathcal{Q} \equiv \operatorname{plim}\left(T^{-1}\left(I_{n} \otimes \tilde{Z}\right) \Sigma_{\tilde{\mathbf{u}}}^{-1}\left(I_{n} \otimes \tilde{Z}^{\prime}\right)\right)$ is well-defined, symmetric and non-singular and $\mathcal{V} \equiv\left(I_{n} \otimes \tilde{Z}\right) \Sigma_{\tilde{\mathbf{u}}}^{-1}\left(I_{n} \otimes \tilde{Z}^{\prime}\right)$.

Proof. Rearranging (18) we obtain

$$
\sqrt{T}(\widehat{\tilde{\boldsymbol{\phi}}}-\tilde{\boldsymbol{\phi}})=\left[\frac{\left(I_{n} \otimes \tilde{Z}\right) \Sigma_{\tilde{\mathbf{u}}}^{-1}\left(I_{n} \otimes \tilde{Z}^{\prime}\right)}{T}\right]^{-1} \frac{\left(I_{n} \otimes \tilde{Z}\right) \Sigma_{\tilde{\mathbf{u}}}^{-1} \tilde{\mathbf{u}}}{\sqrt{T}} .
$$

Expanding the term within squared brackets yields

$$
\frac{\left(I_{n} \otimes \tilde{Z}\right) \Sigma_{\tilde{\mathbf{u}}}^{-1}\left(I_{n} \otimes \tilde{Z}^{\prime}\right)}{T}=\frac{1}{T}\left(\begin{array}{ccccc}
\tilde{Z} \Omega_{11} \tilde{Z}^{\prime} & \tilde{Z} \Omega_{12} \tilde{Z}^{\prime} & \ldots & \tilde{Z} \Omega_{1 n} \tilde{Z}^{\prime} \\
\tilde{Z} \Omega_{21} \tilde{Z}^{\prime} & \tilde{Z} \Omega_{22} \tilde{Z}^{\prime} & \ldots & \tilde{Z} \Omega_{2 n} \tilde{Z}^{\prime} \\
\vdots & \vdots & \ddots & \vdots \\
\tilde{Z} \Omega_{n 1} \tilde{Z}^{\prime} & \tilde{Z} \Omega_{n 2} \tilde{Z}^{\prime} & \ldots & \tilde{Z} \Omega_{n n} \tilde{Z}^{\prime}
\end{array}\right)
$$

where $\Omega_{i j}$ denotes the $T \times T$ block of $\Sigma_{\tilde{\mathbf{u}}}^{-1}$ with $(i, j)$ position. Applying Claim 1, we write

$$
\Omega_{i j}=\omega_{i j, g r} \cdot I_{T}^{g r}+\omega_{i j, n g r} \cdot I_{T}^{n g r},
$$

where $\omega_{i j, g r}$ denotes the component of $\Sigma_{g r}^{-1}$ with $(i, j)$ position. $\omega_{i j, n g r}$ is defined analogously. Substituting for $\Omega_{i j}$ we obtain

$$
\frac{1}{T} \tilde{Z} \Omega_{i j} \tilde{Z}^{\prime}=\omega_{i j, g r} \lambda \sum_{t \in \mathcal{T}^{g r}} \frac{\tilde{z}_{t} \tilde{z}_{t}^{\prime}}{T_{g r}}+\omega_{i j, n g r}(1-\lambda) \sum_{t \notin \mathcal{T} g r} \frac{\tilde{z}_{t} \tilde{z}_{t}^{\prime}}{T_{n g r}},
$$

where $T_{g r}$ and $T_{n g r}$ are used to denote the number of Greek and non-Greek events respectively and $\lambda=\frac{T_{g r}}{T}$ is the sample probability of $t \in \mathcal{T}^{g r}$. Assuming that $\lambda$ converges to a finite number as $T \rightarrow \infty$, the assumptions in (16) and the regularity conditions imposed above ensure that each $\tilde{Z} \Omega_{i j} \tilde{Z}^{\prime}$ has a well-defined probability limit. We can thus write

$$
\frac{\left(I_{n} \otimes \tilde{Z}\right) \Sigma_{\tilde{\mathbf{u}}}^{-1}\left(I_{n} \otimes \tilde{Z}^{\prime}\right)}{T} \stackrel{p}{\rightarrow} \mathcal{Q},
$$

where $\mathcal{Q}$ is a symmetric matrix (since $\Sigma_{\tilde{\mathbf{u}}}^{-1}$ is symmetric) and is non-singular.

Expanding the second term in (19) we get

$$
\frac{\left(I_{n} \otimes \tilde{Z}\right) \Sigma_{\tilde{\mathbf{u}}}^{-1} \tilde{\mathbf{u}}}{\sqrt{T}}=\frac{1}{\sqrt{T}}\left(\begin{array}{c}
\sum_{j=1}^{n} \tilde{Z} \Omega_{1, j} \tilde{u}_{(j)} \\
\sum_{j=1}^{n} \tilde{Z} \Omega_{2, j} \tilde{u}_{(j)} \\
\vdots \\
\sum_{j=1}^{n} \tilde{Z} \Omega_{n, j} \tilde{u}_{(j)}
\end{array}\right)
$$


where

$$
\frac{1}{\sqrt{T}} \sum_{j=1}^{n} \tilde{Z} \Omega_{i, j} \tilde{u}_{(j)}=\sum_{j=1}^{n}\left(\omega_{i j, g r} \sqrt{\lambda} \sum_{t \in \mathcal{T}^{g r}} \frac{\tilde{z}_{t} \tilde{u}_{j, t}}{\sqrt{T_{g r}}}+\omega_{1 j, n g r} \sqrt{1-\lambda} \sum_{t \notin \mathcal{T} g r} \frac{\tilde{z}_{t} \tilde{u}_{j, t}}{\sqrt{T_{n g r}}}\right) .
$$

The terms $\tilde{z}_{t} \tilde{u}_{j, t}$ are martingale difference sequences with well-defined variance-covariance matrices in both Greek and non-Greek regimes. We can therefore apply a version of the Central Limit Theorem (see Hamilton $\left(1994\right.$, p. 193)) to show that each $\frac{1}{\sqrt{T}} \sum_{j=1}^{n} \tilde{Z} \Omega_{i, j} \tilde{u}_{(j)}$ has a well-defined asymptotic normal distribution. Thus, we can write

$$
\frac{\left(I_{n} \otimes \tilde{Z}\right) \Sigma_{\tilde{\mathbf{u}}}^{-1} \tilde{\mathbf{u}}}{\sqrt{T}} \stackrel{d}{\rightarrow} N(\mathbf{0}, \mathcal{V}),
$$

where $\mathcal{V} \equiv\left(I_{n} \otimes \tilde{Z}\right) \Sigma_{\tilde{\mathbf{u}}}^{-1}\left(I_{n} \otimes \tilde{Z}^{\prime}\right)$. Combining (20) and (21), we obtain

$$
\sqrt{T}(\widehat{\widetilde{\phi}}-\tilde{\phi}) \stackrel{d}{\rightarrow} N\left(\mathbf{0}, \mathcal{Q}^{-1} \mathcal{V} \mathcal{Q}^{-1}\right)
$$

\section{A.3 GLS Estimator - Time-Dependent VCV-Matrix and Con- straints}

Consider the following model

$$
y_{t}=\tilde{\Phi} \tilde{z}_{t}+\tilde{u}_{t} \quad \tilde{\Phi}_{(k)}^{\prime}=R_{k} \cdot c_{k}
$$

for $k=1, \ldots, n$. Here $\tilde{\Phi}=\left[\Phi, \delta_{0}, \Delta_{1}\right], \tilde{z}_{t}=\left[z_{t}^{\prime}, \mathbf{1}_{g r, t}, l_{g r, q}^{\prime} \cdot \mathbf{1}_{g r, t}\right]^{\prime}$. Thus, $\Delta_{1}$ denotes a vector of coefficients on the interaction term $l_{g r, q} \cdot \mathbf{1}_{g r, t}$. The equation on the right specifies a set of linear restrictions on each row $\tilde{\Phi}_{(k)}$ of the matrix of coefficients $\tilde{\Phi}$. In particular,

$$
R_{k}=\left(\begin{array}{ccc}
I_{p \times p} & 0_{p \times 1} & 0_{p \times 1} \\
0_{1 \times p} & 1 & 0 \\
0_{n \times p} & 0_{n \times 1} & e^{k}
\end{array}\right) \quad \text { and } \quad c_{k}=\left[\Phi_{(k)}, \delta_{0, k}, \delta_{1}\right]^{\prime}
$$

where $e^{k}$ is the $k^{t h}$ unit vector of length $n$. This set of constraints restricts the components of vector $\Delta_{1}$ to be equal to each other.

The residual process satisfies the following set of assumptions

$$
E_{t}\left(\tilde{u}_{t}\right)=0, \quad E_{t}\left(\tilde{u}_{t} \tilde{u}_{t}^{\prime}\right)=\left\{\begin{array}{ll}
\Sigma_{g r, q} & \text { if } t \in \mathcal{T}_{q} \cap \mathcal{T}^{g r} \\
\Sigma_{n g r, q} & \text { if } t \in \mathcal{T}_{q} \backslash \mathcal{T}^{g r}
\end{array}, \quad E_{t}\left(\tilde{u}_{t} \tilde{u}_{s}^{\prime}\right)=0 \text { for } s \neq t\right.
$$


where $\mathcal{T}_{q}$ is the set of dates in quarter $q$ and $\mathcal{T}^{g r}$ as defined in (4). This formulation allows the variance-covariance matrix of residuals to depend on the quarter $q$ within the two regimes.

Rewriting model (22) using the notation introduced in the previous case, we obtain

$$
\mathbf{y}=\left(I_{n} \otimes \tilde{\mathbb{Z}}^{\prime}\right) \tilde{\phi}+\tilde{\mathbf{u}} \quad \tilde{\boldsymbol{\phi}}=R \cdot \gamma
$$

Here $\tilde{\phi}=\left[\tilde{\Phi}_{(1)}^{\prime}, \tilde{\Phi}_{(2)}^{\prime}, \ldots, \tilde{\Phi}_{(n)}^{\prime}\right]^{\prime}$ is the $n(p+1)+n \times 1$ vector of constrained coefficients obtained from stacking the rows $\tilde{\Phi}_{(k)}$ of matrix $\tilde{\Phi}$, while $\gamma$ is the $n(p+1)+1 \times 1$ vector of unconstrained coefficients and is defined as $\gamma=\left[\Phi_{(1)}^{\prime}, \Phi_{(2)}^{\prime}, \ldots, \Phi_{(n)}^{\prime}, \delta_{0}^{\prime}, \delta_{1}\right]^{\prime}$.

The two coefficients are linearly related through the matrix $R$, which is defined by

$$
R=\left(\begin{array}{cccc}
W & \mathbf{0} & \ldots & E_{1} \\
\mathbf{0} & \ddots & \mathbf{0} & \vdots \\
\vdots & \mathbf{0} & W & E_{n}
\end{array}\right)
$$

where $W$ and $E_{k}$, for $k=1, \ldots, n$ satisfy

$$
W=\left(\begin{array}{c}
I_{p \times p} \\
0_{1 \times p} \\
0_{n \times p}
\end{array}\right) \quad \text { and } \quad E_{k}=\left(\begin{array}{cc}
0_{p \times n} & 0_{p \times 1} \\
e_{k}^{\prime} & 0 \\
0_{n \times n} & e_{k}
\end{array}\right) .
$$

The assumptions (23) on the distribution of the residuals imply that the vector of residuals $\tilde{\mathbf{u}}$ has a variance-covariance matrix that is now equal to

$$
\Sigma_{\tilde{\mathbf{u}}}=\sum_{q}\left\{\Sigma_{q, g r} \otimes\left(I_{T}^{g r} I_{q}\right)+\Sigma_{q, n g r} \otimes\left(I_{T}^{n g r} I_{q}\right)\right\}
$$

where $I_{T}^{g r}$ and $I_{T}^{n g r}$ are defined as above and $I_{q}$ is a $T \times T$ matrix defined as

$$
I_{q}=\left(\begin{array}{lllllll}
0_{T_{1} \times T_{1}} & \ldots & \ldots & \ldots & \ldots & \ldots & \ldots \\
\ldots & \ldots & 0_{T_{q-1} \times T_{q-1}} & 0_{T_{q-1} \times T_{q}} & \ldots & \ldots & \ldots \\
\ldots & \ldots & 0_{T_{q-1} \times T_{q}} & I_{T_{q} \times T_{q}} & 0_{T_{q} \times T_{q+1}} & \ldots & \ldots \\
\ldots & \ldots & \ldots & \ldots & \ldots & \ldots & \ldots \\
\ldots & \ldots & \ldots & \ldots & \ldots & \ldots & 0_{T_{Q} \times T_{Q}}
\end{array}\right)
$$

where $0_{T_{q} \times T_{q}}$ and $I_{T_{q} \times T_{q}}$ denote a zero matrix and an identity matrix with dimension $T_{q} \times T_{q}$, respectively.

We now derive an estimator for this model under this set of assumptions. Substituting the constraint into the main equation, the GLS estimator of $\gamma$ minimizes the expression

$$
\tilde{\mathbf{u}}^{\prime}\left(\Sigma_{\tilde{\mathbf{u}}}\right)^{-1} \tilde{\mathbf{u}}=\left(\mathbf{y}-\left(I_{n} \otimes \tilde{Z}^{\prime}\right) R \boldsymbol{\gamma}\right)^{\prime} \Sigma_{\tilde{\mathbf{u}}}^{-1}\left(\mathbf{y}-\left(I_{n} \otimes \tilde{Z}^{\prime}\right) R \boldsymbol{\gamma}\right)
$$


The estimator of $\gamma$ is thus

$$
\hat{\gamma}=\left[R^{\prime}\left(I_{n} \otimes \tilde{\mathbb{Z}}\right) \Sigma_{\mathbf{u}}^{-1}\left(I_{n} \otimes \tilde{\mathbb{Z}}^{\prime}\right) R\right]^{-1} R^{\prime}\left(I_{n} \otimes \tilde{\mathbb{Z}}^{\prime}\right) \Sigma_{\mathbf{u}}^{-1} \mathbf{y}
$$

Under the assumptions in (23) and the same regularity conditions as before, we can show

Claim 3 The GLS estimator $\hat{\gamma}$ converges in distribution according to

$$
\sqrt{T}(\hat{\gamma}-\gamma) \stackrel{d}{\rightarrow} N\left(\mathbf{0}, \mathcal{Q}^{-1} \mathcal{V} \mathcal{Q}^{-1}\right)
$$

where $\mathcal{Q} \equiv \operatorname{plim}\left(T^{-1}\left(R^{\prime}\left(I_{n} \otimes \tilde{Z}\right) \Sigma_{\tilde{\mathbf{u}}}^{-1}\left(I_{n} \otimes \tilde{Z}^{\prime}\right) R\right)\right)$ is well-defined, symmetric and nonsingular and $\mathcal{V} \equiv R^{\prime}\left(I_{n} \otimes \tilde{Z}^{\prime}\right) \Sigma_{\tilde{\mathbf{u}}}^{-1}\left(I_{n} \otimes \tilde{Z}\right) R$.

Proof. Rearranging (26) we obtain

$$
\sqrt{T}(\hat{\gamma}-\gamma)=\left[\frac{R^{\prime}\left(I_{n} \otimes \tilde{Z}\right) \Sigma_{\tilde{\mathbf{u}}}^{-1}\left(I_{n} \otimes \tilde{Z}^{\prime}\right) R}{T}\right]^{-1} \frac{R^{\prime}\left(I_{n} \otimes \tilde{Z}^{\prime}\right) \Sigma_{\tilde{\mathbf{u}}}^{-1} \tilde{\mathbf{u}}}{\sqrt{T}}
$$

The expansion of the term within squared bracket yields

$\frac{R^{\prime}\left(I_{n} \otimes \tilde{Z}\right) \Sigma_{\tilde{\mathbf{u}}}^{-1}\left(I_{n} \otimes \tilde{Z}^{\prime}\right) R}{T}=$

$=\frac{1}{T}\left(\begin{array}{cccc}W^{\prime} \tilde{Z} & 0 & \ldots & 0 \\ 0 & W^{\prime} \tilde{Z} & \ldots & 0 \\ \vdots & \vdots & \ddots & \vdots \\ 0 & 0 & \ldots & W^{\prime} \tilde{Z} \\ E_{1}^{\prime} \tilde{Z} & E_{2}^{\prime} \tilde{Z} & \ldots & E_{n}^{\prime} \tilde{Z}\end{array}\right)\left(\begin{array}{cccc}\Omega_{11} & \Omega_{12} & \ldots & \Omega_{1 n} \\ \Omega_{21} & \Omega_{22} & \ldots & \Omega_{2 n} \\ \vdots & \vdots & \ddots & \vdots \\ \Omega_{n 1} & \Omega_{n 2} & \ldots & \Omega_{n n}\end{array}\right)\left(\begin{array}{ccccc}\tilde{Z}^{\prime} W & 0 & \ldots & \ldots & \tilde{Z}^{\prime} E_{1} \\ 0 & \tilde{Z}^{\prime} W & \ldots & \ldots & \tilde{Z}^{\prime} E_{2} \\ \vdots & \vdots & \ddots & \ldots & \vdots \\ 0 & 0 & \ldots & \tilde{Z}^{\prime} W & \tilde{Z}^{\prime} E_{n}\end{array}\right)$

$=\frac{1}{T}\left(\begin{array}{ccccc}W^{\prime} \tilde{Z} \Omega_{11} \tilde{Z}^{\prime} W & W^{\prime} \tilde{Z} \Omega_{12} \tilde{Z}^{\prime} W & \ldots & \ldots & \sum_{j} W^{\prime} \tilde{Z} \Omega_{1 j} \tilde{Z}^{\prime} E_{j} \\ W^{\prime} \tilde{Z} \Omega_{21} \tilde{Z}^{\prime} W & W^{\prime} \tilde{Z} \Omega_{22} \tilde{Z}^{\prime} W & \ldots & \ldots & \sum_{j} W^{\prime} \tilde{Z} \Omega_{2 j} \tilde{Z}^{\prime} E_{j} \\ \vdots & \vdots & \ddots & \ldots & \ldots \\ \vdots & \vdots & \ldots & W^{\prime} \tilde{Z} \Omega_{n n} \tilde{Z}^{\prime} W & \sum_{j} W^{\prime} \tilde{Z} \Omega_{n j} \tilde{Z}^{\prime} E_{j} \\ \sum_{i} E_{i}^{\prime} \tilde{Z} \Omega_{i 1} \tilde{Z}^{\prime} W & \sum_{i} E_{i}^{\prime} \tilde{Z} \Omega_{i 2} \tilde{Z}^{\prime} W & \ldots & \sum_{i} E_{i}^{\prime} \tilde{Z} \Omega_{i n} \tilde{Z}^{\prime} W & \sum_{j}\left(\sum_{i} E_{i}^{\prime} \tilde{Z} \Omega_{i j} \tilde{Z}^{\prime} E_{j}\right)\end{array}\right)$

where $\Omega_{i j}$ is used again to indicate the $T \times T$ block of matrix $\Sigma_{\mathbf{u}}$ with $(i, j)$ position.

We can further rearrange this equation. To do so, we need first to realize that the matrix $\Omega_{i j}$ is now formed by different submatrices which account for the varying covariance 
of residuals across quarters:

$$
\Omega_{i j}=\left(\begin{array}{cccc}
\Omega_{i j, 1} & 0 & \ldots & 0 \\
0 & \Omega_{i j, 2} & \ldots & 0 \\
\vdots & \vdots & \ddots & \vdots \\
0 & 0 & \ldots & \Omega_{i j, Q}
\end{array}\right)
$$

Let $I_{g r, q}$ define the non-zero diagonal submatrix with $T_{q} \times T_{q}$ dimension of the matrix $I_{T}^{g r} \cdot I_{q}$. Matrix $I_{n g r, q}$ is defined analogously. Applying Claim 1, we write

$$
\Omega_{i j, q}=\omega_{i j, g r, q} \cdot I_{g r, q}+\omega_{i j, n g r, q} \cdot I_{n g r, q}
$$

where $\omega_{i j, g r, q}$ and $\omega_{i j, n g r, q}$ denote the components with $(i, j)$ position of $\Sigma_{g r, q}^{-1}$ and $\Sigma_{n g r, q}^{-1}$, respectively.

Using the definitions of $\Omega_{i j}, W$ and each $E_{i}$, we can now show that the blocks of the expanded matrix in (28) contains the uncentered second moments of the regressors in $\tilde{z}_{t}$ and thus must have a well-defined probability limit. Consider a partition of the previously defined matrix $\tilde{Z}$ into a number of submatrices $\tilde{Z}_{q}$ which are formed by the time series of $\tilde{z}_{t}$ within each quarter $q$. Thus, $\tilde{Z}=\left[\tilde{Z}_{1}, \ldots, \tilde{Z}_{Q}\right]$. We can show first that

$$
\frac{1}{T} W^{\prime} \tilde{Z} \Omega_{i j} \tilde{Z}^{\prime} W=\frac{1}{T} Z \Omega_{i j} Z^{\prime}=\sum_{q=1}^{Q} \frac{1}{T} Z_{q} \Omega_{i j, q} Z_{q}^{\prime}
$$

and, by the above decomposition of $\Omega_{i j, q}$, each element in the sum can be expressed as

$$
\frac{1}{T} Z_{q} \Omega_{i j, q} Z_{q}^{\prime}=n\left(\omega_{i j, g r, q} \lambda_{q} \sum_{t \in \mathcal{T}_{q}} \frac{z_{t} z_{t}^{\prime}}{T_{g r, q}}+\omega_{i j, n g r, q}\left(1-\lambda_{q}\right) \sum_{t \in T_{q} \backslash \mathcal{T}_{q}} \frac{z_{t} z_{t}^{\prime}}{T_{n g r, q}}\right),
$$

where $\lambda_{q}, T_{g r, q}$ and $T_{n g r, q}$ are defined as before but now depend on a specific quarter $q$ and $n=P(t$ in quarter $q)$ denotes the sample probability of a date $t$ being in quarter $q$. Assuming that the limits for $\lambda_{q}$ and $n$ as $T \rightarrow \infty$ exist and are finite, our set of assumptions ensures that $\frac{1}{T} Z_{q} \Omega_{i j, q} Z_{q}^{\prime}$ converges in probability. We can thus write

$$
\frac{1}{T} W^{\prime} \tilde{Z} \Omega_{i j} \tilde{Z}^{\prime} W \stackrel{p}{\rightarrow} \mathcal{Q}_{i j}
$$

where $\mathcal{Q}$ is a symmetric matrix (since $\Sigma_{\mathbf{u}}^{-1}$ is symmetric) and is assumed to be non-singular.

Using a similar rearrangement, we can also show that

$$
\frac{1}{T} E_{i}^{\prime} \tilde{Z} \Omega_{i j} \tilde{Z}^{\prime} W=\sum_{q=1}^{Q} \frac{1}{T} E_{i}^{\prime} \tilde{Z}_{q} \Omega_{i j, q} Z_{q}^{\prime}
$$


where for each $q$ it holds

$$
E_{i}^{\prime} \tilde{Z}_{q} \Omega_{i j, q} Z_{q}^{\prime}=n\left(\omega_{i j, g r, q} \lambda_{q} \sum_{t \in \mathcal{T}_{q}} \frac{\tilde{e}_{i, t} z_{t}^{\prime}}{T_{g r, q}}+\omega_{i j, n g r, q}\left(1-\lambda_{q}\right) \sum_{t \in T_{q} \backslash \mathcal{T}_{q}} \frac{\tilde{e}_{i, t} z_{t}^{\prime}}{T_{n g r, q}}\right) .
$$

Here $\tilde{e}_{i, t} \equiv E_{i}^{\prime} \tilde{z}_{t}=\left[\left(e_{i} \cdot \mathbf{1}_{g r, t}\right)^{\prime},\left(e_{i}^{\prime} \cdot\left(l_{g r, q} \cdot \mathbf{1}_{g r, t}\right)\right)^{\prime}\right]^{\prime}$ is a $(n+1) \times 1$ vector which includes the indicator $\mathbf{1}_{g r, t}$ in the $i^{\text {th }}$ position and the interaction between the Greek indicator and the $i^{\text {th }}$ component of vector $l_{g r, q}$ in the $(n+1)^{t h}$ position. As this term has a well-defined limit under our regularity assumptions, we can conclude that the matrix $\frac{1}{T} E_{i}^{\prime} \tilde{Z} \Omega_{i j} \tilde{Z}^{\prime} W$ converges in probability and thus

$$
\frac{1}{T} \sum_{i} E_{i}^{\prime} \tilde{Z} \Omega_{i j} \tilde{Z}^{\prime} W \stackrel{p}{\rightarrow} \mathcal{E}_{i j}
$$

where $\mathcal{E}_{i j}$ is well-defined. Finally, we can show analougsly that

$$
\sum_{j}\left(\sum_{i} E_{i}^{\prime} \tilde{Z} \Omega_{i j} \tilde{Z}^{\prime} E_{j}\right) \stackrel{p}{\rightarrow} \mathcal{H}
$$

where $\mathcal{H}$ is well-defined. Combining these three results, we obtain

$$
\frac{R^{\prime}\left(I_{n} \otimes \tilde{Z}\right) \Sigma_{\tilde{\mathbf{u}}}^{-1}\left(I_{n} \otimes \tilde{Z}^{\prime}\right) R}{T} \stackrel{p}{\rightarrow} \mathcal{Q}
$$

where $\mathcal{Q}$ is well-defined, symmetric and non-singular.

Given the assumption that the residual $u_{t}$ is conditional independent of the regressors in $\tilde{z}_{t}$, we can now apply the Central Limit Theorem, as we did in the previous case, and we can show that the second term in (27) has a well-defined asymptotic distribution:

$$
\frac{R^{\prime}\left(I_{n} \otimes \tilde{Z}^{\prime}\right) \Sigma_{\tilde{\mathbf{u}}}^{-1} \tilde{\mathbf{u}}}{\sqrt{T}} \stackrel{d}{\rightarrow} N(\mathbf{0}, \mathcal{V})
$$

where $\mathcal{V} \equiv R^{\prime}\left(I_{n} \otimes \tilde{Z}^{\prime}\right) \Sigma_{\tilde{\mathbf{u}}}^{-1}\left(I_{n} \otimes \tilde{Z}\right) R$. Combining (29) and (30) we obtain

$$
\sqrt{T}(\hat{\gamma}-\gamma) \stackrel{d}{\rightarrow} N\left(\mathbf{0}, \mathcal{Q}^{-1} \mathcal{V} \mathcal{Q}^{-1}\right)
$$


Table 1: Pairwise Correlations of Changes in Sovereign CDS for 10 European Countries Log changes by business day, January 12009 to December 312010

\begin{tabular}{|c|c|c|c|c|c|c|c|c|c|c|}
\hline Belgium & 0.7667 & & & & & & & & & \\
\hline Germany & 0.7286 & 0.7387 & & & & & & & & \\
\hline Italy & 0.7427 & 0.767 & 0.7103 & 0.7503 & 0.742 & & & & & \\
\hline Netherlands & 0.7584 & 0.7967 & 0.7337 & 0.7467 & 0.6266 & 0.7356 & & & & \\
\hline Portugal & 0.7113 & 0.737 & 0.6808 & 0.7402 & 0.8012 & 0.8409 & 0.7042 & & & \\
\hline Sweden & 0.7687 & 0.708 & 0.7018 & 0.6979 & 0.6001 & 0.671 & 0.7305 & 0.6458 & & \\
\hline Spain & 0.724 & 0.7676 & 0.7187 & 0.7337 & 0.7817 & 0.8915 & 0.7169 & 0.8835 & 0.6696 & \\
\hline UK & 0.7469 & 0.7579 & 0.6699 & 0.7161 & 0.6106 & 0.7427 & 0.7354 & 0.7223 & 0.6902 & 0.7112 \\
\hline
\end{tabular}

Source: Datastream, own calculations. 
Table 2a: Summary Statistics - Exposure to Greek Debt, Time-Average in \% of GDP, Average 2009/10

\begin{tabular}{lccc}
\hline \hline & Total Debt & Public Debt & Bank Debt \\
\cline { 2 - 4 } mean & $0.75 \%$ & $0.48 \%$ & $0.09 \%$ \\
std. dev. & $0.46 \%$ & $0.32 \%$ & $0.07 \%$ \\
min & $0.08 \%$ & $0.04 \%$ & $0.00 \%$ \\
max & $1.22 \%$ & $0.78 \%$ & $0.21 \%$ \\
\hline No. Countries & 10 & 10 & 10 \\
\hline \hline
\end{tabular}

Source: BIS Consolidated Banking Statistics. Countries are: Austria, Belgium, Germany, Spain, France, UK, Italy, the Netherlands, Portugal and Sweden.

Table 2b: Summary Statistics - Exposure to Greek Debt, Evolution Quarterly data, normalized $2009 Q 4=100$

\begin{tabular}{|c|c|c|c|c|c|}
\hline & \multicolumn{5}{|c|}{ A.Total Debt } \\
\hline & $2009 Q 4$ & $2010 Q 1$ & $2010 Q 2$ & $2010 Q 3$ & $2010 Q 4$ \\
\hline mean & $100 \%$ & $100.2 \%$ & $69.4 \%$ & $74.6 \%$ & $62.6 \%$ \\
\hline std. dev. & $0 \%$ & $17.7 \%$ & $15.0 \%$ & $17.2 \%$ & $23.0 \%$ \\
\hline $\min$ & $100 \%$ & $76.9 \%$ & $41.6 \%$ & $40.3 \%$ & $21.2 \%$ \\
\hline \multirow[t]{3}{*}{$\max$} & $100 \%$ & $143.0 \%$ & $94.3 \%$ & $95.8 \%$ & $92.6 \%$ \\
\hline & \multicolumn{5}{|c|}{ B. Public Debt } \\
\hline & $2009 Q 4$ & $2010 Q 1$ & $2010 Q 2$ & $2010 Q 3$ & $2010 Q 4$ \\
\hline mean & $100 \%$ & $108.8 \%$ & $74.9 \%$ & $80.7 \%$ & $67.8 \%$ \\
\hline std. dev. & $0 \%$ & $28.8 \%$ & $26.3 \%$ & $30.0 \%$ & $32.4 \%$ \\
\hline $\min$ & $100 \%$ & $80.0 \%$ & $20.3 \%$ & $16.7 \%$ & $16.4 \%$ \\
\hline \multirow[t]{3}{*}{$\max$} & $100 \%$ & $166.6 \%$ & $105.0 \%$ & $115.2 \%$ & $105.0 \%$ \\
\hline & \multicolumn{5}{|c|}{ C. Bank Debt } \\
\hline & $2009 Q 4$ & $2010 Q 1$ & $2010 Q 2$ & $2010 Q 3$ & $2010 Q 4$ \\
\hline mean & $100 \%$ & $86.5 \%$ & $66.3 \%$ & $56.0 \%$ & $29.7 \%$ \\
\hline std. dev. & $0 \%$ & $54.5 \%$ & $65.9 \%$ & $70.2 \%$ & $28.2 \%$ \\
\hline $\min$ & $100 \%$ & $8.8 \%$ & $16.3 \%$ & $7.5 \%$ & $2.2 \%$ \\
\hline $\max$ & $100 \%$ & $215.0 \%$ & $236.6 \%$ & $251.6 \%$ & $96.7 \%$ \\
\hline No. Countries & 10 & 10 & 10 & 10 & 10 \\
\hline
\end{tabular}


Table 3a: Baseline GLS Estimation Results - logged CDS

\begin{tabular}{|c|c|c|c|c|c|c|c|c|c|c|c|}
\hline & $\begin{array}{l}\text { AT } \\
\end{array}$ & 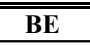 & 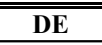 & $\overline{E \text { ES }}$ & 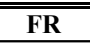 & 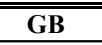 & 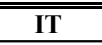 & $\begin{array}{l}\mathbf{N L} \\
\end{array}$ & 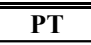 & $\overline{\overline{\text { SE }}}$ & 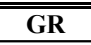 \\
\hline GR & $\begin{array}{c}0.0199 \\
0.0097\end{array}$ & $\begin{array}{c}0.0239 \\
0.0104\end{array}$ & $\begin{array}{c}0.0132 \\
0.0094\end{array}$ & $\begin{array}{c}0.0277 \\
0.0133\end{array}$ & $\begin{array}{c}0.0299 \\
0.0093\end{array}$ & $\begin{array}{c}0.0233 \\
0.0088\end{array}$ & $\begin{array}{c}0.0310 \\
0.0133\end{array}$ & $\begin{array}{c}0.0113 \\
0.0081\end{array}$ & $\begin{array}{c}0.0297 \\
0.0150\end{array}$ & $\begin{array}{c}0.0213 \\
0.0081\end{array}$ & $\begin{array}{c}0.0722 \\
0.0147\end{array}$ \\
\hline Rsq & 0.29 & 0.31 & 0.33 & 0.34 & 0.35 & 0.32 & 0.36 & 0.34 & 0.43 & 0.29 & 0.42 \\
\hline Obs. & 514 & 514 & 514 & 514 & 514 & 514 & 514 & 514 & 514 & 514 & 514 \\
\hline \multirow[t]{2}{*}{ RResp } & 0.2755 & 0.3314 & 0.1833 & 0.3833 & 0.4143 & 0.3222 & 0.4292 & 0.1564 & 0.4107 & 0.2948 & \\
\hline & \multicolumn{10}{|c|}{ Bootstrap Results } & \\
\hline mean (bootstr) & 0.2633 & 0.3293 & 0.1756 & 0.3641 & 0.4074 & 0.3190 & 0.3938 & 0.1427 & 0.3612 & 0.2967 & \\
\hline .005 per-tile & -0.0779 & 0.0236 & -0.2095 & -0.2109 & 0.1501 & -0.0286 & -0.2743 & -0.2216 & -0.4143 & 0.0122 & \\
\hline .025 per-tile & 0.0179 & 0.0972 & -0.0921 & -0.0102 & 0.2097 & 0.0645 & -0.0219 & -0.1045 & -0.0729 & 0.0994 & \\
\hline .975 per-tile & 0.4442 & 0.5666 & 0.4066 & 0.7392 & 0.6044 & 0.5860 & 0.7848 & 0.3355 & 0.7539 & 0.4974 & \\
\hline .995 per-tile & 0.5159 & 0.6372 & 0.4775 & 0.8560 & 0.6815 & 0.7087 & 0.8890 & 0.3921 & 0.9085 & 0.5579 & \\
\hline
\end{tabular}

Note: Dependent Variable vector of CDS spreads, logged. Countries are: Austria, Belgium, Germany, Spain, France, UK, Italy, the Netherlands, Portugal, Sweden and Greece. The underlying model is as specified in equation (6). Exogenous variables are CDS for US and Japan, VIX of the US, all logged and lagged, federal fund rate, S\&P market returns, both lagged, and weekday dummies. Eight lags of the dependent variables are included, non of the exogenous variables. All CDS spreads and the VIX are in first differences to remove a stochastic trend.

Table 3b: Baseline GLS Estimation Results - CDS in basis points

\begin{tabular}{|c|c|c|c|c|c|c|c|c|c|c|c|}
\hline & 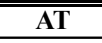 & 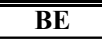 & 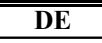 & 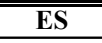 & 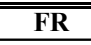 & 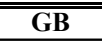 & 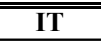 & 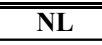 & 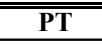 & 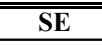 & 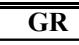 \\
\hline GR & $\begin{array}{c}1.151 \\
0.837\end{array}$ & $\begin{array}{c}1.441 \\
0.921\end{array}$ & $\begin{array}{c}0.503 \\
0.408\end{array}$ & $\begin{array}{c}4.870 \\
2.325\end{array}$ & $\begin{array}{c}1.686 \\
0.517\end{array}$ & $\begin{array}{c}1.825 \\
0.661\end{array}$ & $\begin{array}{c}4.611 \\
1.874\end{array}$ & $\begin{array}{c}0.369 \\
0.436\end{array}$ & $\begin{array}{c}8.510 \\
4.502\end{array}$ & $\begin{array}{c}0.696 \\
0.394\end{array}$ & $\begin{array}{r}37.783 \\
9.329\end{array}$ \\
\hline $\begin{array}{l}\text { Rsq } \\
\text { Obs. }\end{array}$ & $\begin{array}{l}0.37 \\
514\end{array}$ & $\begin{array}{l}0.42 \\
514\end{array}$ & $\begin{array}{l}0.43 \\
514\end{array}$ & $\begin{array}{l}0.45 \\
514\end{array}$ & $\begin{array}{c}0.43 \\
514\end{array}$ & $\begin{array}{l}0.41 \\
514\end{array}$ & $\begin{array}{l}0.45 \\
514\end{array}$ & $\begin{array}{l}0.42 \\
514\end{array}$ & $\begin{array}{c}0.50 \\
514\end{array}$ & $\begin{array}{l}0.38 \\
514\end{array}$ & $\begin{array}{l}0.53 \\
514\end{array}$ \\
\hline RResp & 0.0305 & 0.0381 & 0.0133 & 0.1289 & 0.0446 & 0.0483 & 0.1220 & 0.0098 & 0.2252 & 0.0184 & \\
\hline & \multicolumn{11}{|c|}{ Bootstrap Results } \\
\hline mean (bootstr) & 0.0343 & 0.0390 & 0.0144 & 0.1254 & 0.0464 & 0.0529 & 0.1194 & 0.0120 & 0.1939 & 0.0219 & \\
\hline .005 per-tile & -0.0345 & -0.0410 & -0.0259 & -0.1143 & 0.0208 & -0.0035 & -0.1148 & -0.0257 & -0.3816 & -0.0040 & \\
\hline .025 per-tile & -0.0067 & -0.0180 & -0.0108 & -0.0162 & 0.0256 & 0.0125 & 0.0033 & -0.0163 & -0.1409 & 0.0031 & \\
\hline .975 per-tile & 0.0823 & 0.0899 & 0.0405 & 0.2427 & 0.0698 & 0.1150 & 0.2303 & 0.0379 & 0.4191 & 0.0473 & \\
\hline .995 per-tile & 0.1182 & 0.1121 & 0.0451 & 0.2883 & 0.0785 & 0.1530 & 0.2690 & 0.0586 & 0.4655 & 0.0771 & \\
\hline
\end{tabular}

Note: Dependent Variable vector of CDS spreads, in levels (bp). Countries are: Austria, Belgium, Germany, Spain, France, UK, Italy, the Netherlands, Portugal, Sweden and Greece. The underlying model is as specified in equation (6). Exogenous variables are CDS for US and Japan, VIX of the US, all logged and lagged, federal fund rate, S\&P market returns, both lagged, and weekday dummies. Eight lags of the dependent variables are included, non of the exogenous variables. All CDS spreads and the VIX are in first differences to remove a stochastic trend. 
Table 4: GLS with Financial Linkages

\begin{tabular}{|c|c|c|c|}
\hline & I & II & III \\
\hline GR & $\begin{array}{c}0.0737 \\
0.0143\end{array}$ & $\begin{array}{c}0.0737 \\
0.0143\end{array}$ & $\begin{array}{c}0.0738 \\
0.0143\end{array}$ \\
\hline GR*Total & $\begin{array}{c}0.0207 \\
0.0067\end{array}$ & & \\
\hline GR*Publ & & $\begin{array}{c}0.0140 \\
0.0040\end{array}$ & \\
\hline GR*Bank & & & $\begin{array}{c}0.0066 \\
0.0020\end{array}$ \\
\hline $\begin{array}{l}d \text { (Total) } \\
d \text { (Public) } \\
d \text { (Bank) }\end{array}$ & 0.2809 & 0.1893 & 0.0900 \\
\hline$d$ (Bank) & \multicolumn{3}{|c|}{ Bootstrap Results } \\
\hline mean (bootstr) & 0.3074 & 0.2088 & 0.0796 \\
\hline .005 per-tile & 0.1150 & 0.0922 & 0.0263 \\
\hline .025 per-tile & 0.1578 & 0.1101 & 0.0370 \\
\hline .975 per-tile & 0.4937 & 0.3295 & 0.1291 \\
\hline .995 per-tile & 0.5717 & 0.3679 & 0.1524 \\
\hline
\end{tabular}

Note: Dependent variable vector of CDS, log changes. Countries are: Austria, Belgium, Germany, Spain, France, UK, Italy, the Netherlands, Portugal, Sweden and Greece. The underlying model is as specified in equation (11). Exogenous variables are CDS for US and Japan, logged and lagged, VIX of the US, federal fund rate, S\&P market returns and weekday dummies. Eight lags of the dependent variables are included, non of the exogenous variables. 
Table 5: Financial Linkages - Percentage Exposure

\begin{tabular}{|c|c|c|c|}
\hline & $\mathbf{I}$ & II & III \\
\hline GR & $\begin{array}{c}38.0628 \\
9.2571\end{array}$ & $\begin{array}{c}38.0331 \\
9.2576\end{array}$ & $\begin{array}{c}37.5763 \\
9.2616\end{array}$ \\
\hline GR*Total & $\begin{array}{c}55.5008 \\
43.3795\end{array}$ & & \\
\hline GR*Publ & & $\begin{array}{c}224.6392 \\
52.6591\end{array}$ & \\
\hline GR*Bank & & & $\begin{array}{c}846.6421 \\
196.0258\end{array}$ \\
\hline $\begin{array}{l}d \text { (Total) } \\
d \text { (Public) } \\
d \text { (Bank) }\end{array}$ & 1.4581 & 5.9064 & 22.5313 \\
\hline$d$ (Bank) & \multicolumn{3}{|c|}{ Bootstrap Results } \\
\hline mean (bootstr) & 1.5660 & 5.4854 & 20.5417 \\
\hline .005 per-tile & -0.8981 & 2.1960 & 8.4222 \\
\hline .025 per-tile & -0.4493 & 2.9890 & 10.7905 \\
\hline .975 per-tile & 3.8242 & 8.4531 & 32.9807 \\
\hline .995 per-tile & 4.6547 & 10.0328 & 35.9342 \\
\hline
\end{tabular}

Note: Dependent variable vector of CDS, changes of levels (bp). The model is specified in equation (11). Countries are: Austria, Belgium, Germany, Spain, France, UK, Italy, the Netherlands, Portugal, Sweden and Greece. See also Note of Table 2. 
Table 6: Financial Linkages - Excluding BE, NL and $S E$

\begin{tabular}{|c|c|c|c|}
\hline & $\mathbf{I}$ & II & III \\
\hline GR & $\begin{array}{c}0.0722 \\
0.0150\end{array}$ & $\begin{array}{c}0.0721 \\
0.0150\end{array}$ & $\begin{array}{c}0.0714 \\
0.0149\end{array}$ \\
\hline GR*Total & $\begin{array}{c}0.0125 \\
0.0144\end{array}$ & & \\
\hline GR*Publ & & $\begin{array}{c}0.0348 \\
0.0118\end{array}$ & \\
\hline GR*Bank & & & $\begin{array}{c}0.0117 \\
0.0042\end{array}$ \\
\hline $\begin{array}{l}d \text { (Total) } \\
d \text { (Public) } \\
d \text { (Bank) }\end{array}$ & 0.1736 & 0.4823 & 0.1641 \\
\hline$d$ (Bank) & \multicolumn{3}{|c|}{ Bootstrap Results } \\
\hline mean (bootstr) & 0.1706 & 0.4986 & 0.1358 \\
\hline .005 per-tile & -0.3746 & 0.1948 & 0.0268 \\
\hline .025 per-tile & -0.2605 & 0.2570 & 0.0439 \\
\hline .975 per-tile & 0.4833 & 0.7639 & 0.2287 \\
\hline .995 per-tile & 0.6041 & 0.8444 & 0.2444 \\
\hline
\end{tabular}

Note: Dependent variable vector of CDS, log changes. The model is specified in equation (11). Countries are: Austria, Germany, Spain, France, UK, Italy, Portugal and Greece. See also Note of Table 2. 
Table 7: Financial Linkages - Excluding UK and Sweden

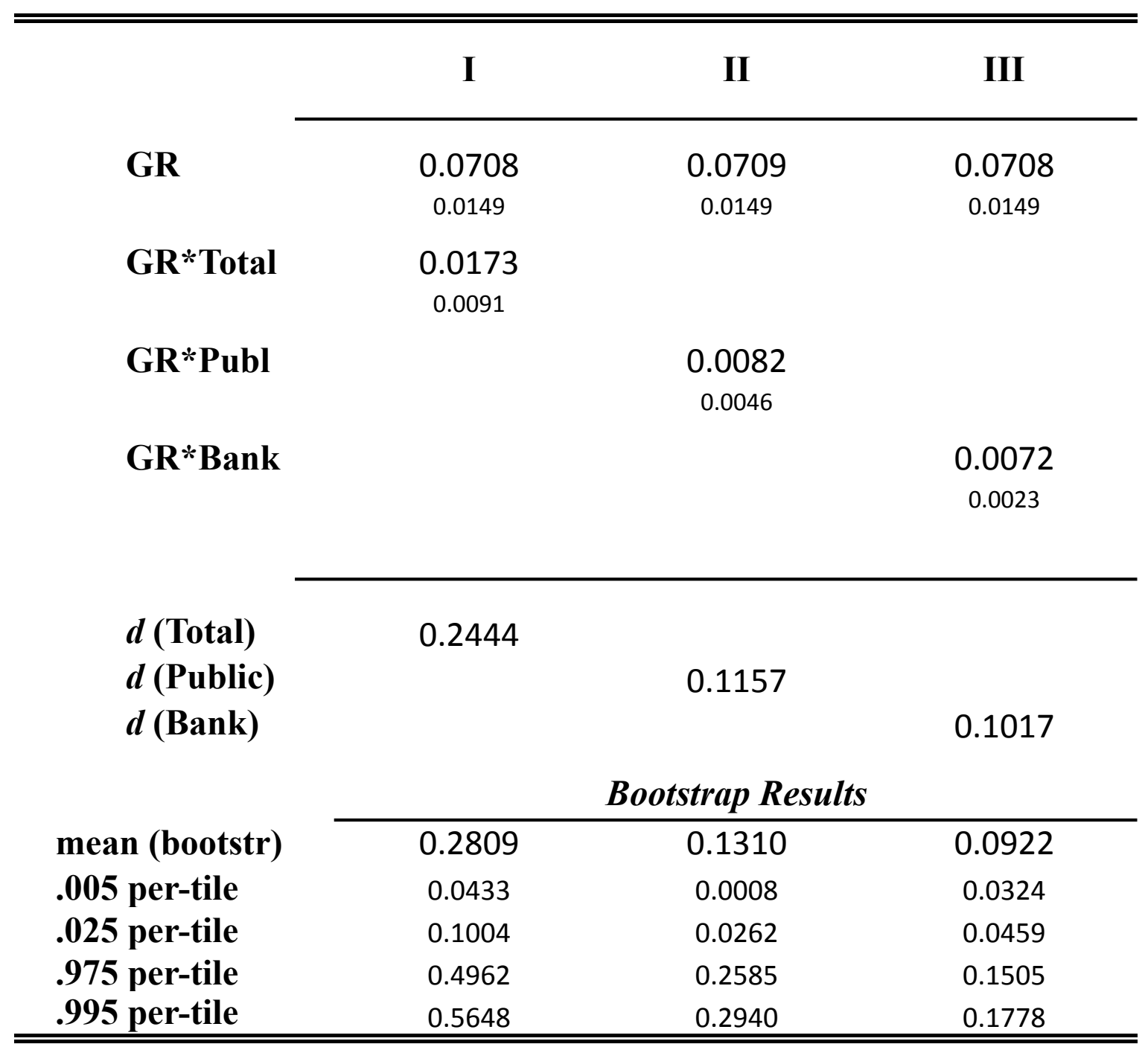

Note: Dependent variable vector of CDS, log changes. The model is specified in equation (11). Countries are: Austria, Belgium, Germany, Spain, France, Italy, the Netherlands, Portugal and Greece. See also Note of Table 2. 
Table 8: Financial Linkages - Indirect Linkages

\begin{tabular}{|c|c|c|c|}
\hline & I & II & III \\
\hline GR & $\begin{array}{c}0.0735 \\
0.0143\end{array}$ & $\begin{array}{c}0.0736 \\
0.0143\end{array}$ & $\begin{array}{c}0.0739 \\
0.0143\end{array}$ \\
\hline GR*Total & $\begin{array}{c}0.0242 \\
0.0103\end{array}$ & & \\
\hline GR*Publ & & $\begin{array}{c}0.0149 \\
0.0046\end{array}$ & \\
\hline GR*Bank & & & $\begin{array}{c}0.0074 \\
0.0030\end{array}$ \\
\hline$d$ (Total) & 0.3293 & & \\
\hline$d$ (Public) & & 0.2024 & \\
\hline \multirow[t]{2}{*}{$d$ (Bank) } & & & 0.1001 \\
\hline & \multicolumn{3}{|c|}{ Bootstrap Results } \\
\hline mean (bootstr) & 0.3756 & 0.2287 & 0.0865 \\
\hline .005 per-tile & 0.1116 & 0.0970 & -0.0092 \\
\hline .025 per-tile & 0.1700 & 0.1183 & 0.0184 \\
\hline .975 per-tile & 0.6435 & 0.3571 & 0.1563 \\
\hline .995 per-tile & 0.7011 & 0.3965 & 0.1872 \\
\hline
\end{tabular}

Note: Dependent variable vector of CDS, log changes. The model is specified in equation (11). Countries are: Austria, Belgium, Germany, Spain, France, UK, Italy, the Netherlands, Portugal, Sweden and Greece. See also Note of Table 2. 